University of Wollongong

Research Online

Faculty of Engineering and Information

Faculty of Engineering and Information

Sciences - Papers: Part B

Sciences

2017

\title{
Reinforced concrete beams strengthened in flexure with near-surface mounted (NSM) CFRP strips: Current status and research needs
}

Shi Shun Zhang

University of Wollongong, shishun@uow.edu.au

Tao Yu

University of Wollongong, taoy@uow.edu.au

G M. Chen

Guangdong University of Technology

Follow this and additional works at: https://ro.uow.edu.au/eispapers1

Part of the Engineering Commons, and the Science and Technology Studies Commons

Research Online is the open access institutional repository for the University of Wollongong. For further information contact the UOW Library: research-pubs@uow.edu.au 


\title{
Reinforced concrete beams strengthened in flexure with near-surface mounted (NSM) CFRP strips: Current status and research needs
}

\author{
Abstract \\ The near-surface mounted (NSM) FRP strengthening technique has attracted worldwide attention as an \\ effective alternative to the externally bonded (EB) FRP strengthening technique. In the NSM FRP \\ strengthening method, grooves are first cut in the concrete cover of a concrete member for the FRP \\ reinforcement to be inserted and embedded using an adhesive. The NSM FRP method has many \\ advantages over the EB FRP method, including a higher bonding efficiency and a better protection of the \\ FRP reinforcement. Existing experimental studies have shown that FRP strips owned a better bond \\ efficiency compared with other section shapes (e.g. round bars and square bars), due to the fact that they \\ had a larger perimeter-to-cross-sectional area ratio. This paper presents a state-of-the-art review, \\ particularly on the flexural strengthening of RC beams with NSM CFRP strips. The observed failure modes \\ in laboratory experiments of such FRP-strengthened RC beams are classified and the existing strength \\ models are examined along with the failure mechanisms behind. The main knowledge gaps to be bridged \\ in future studies are also identified. This review partially formed the basis of the development of design \\ provisions on the NSM strengthening technique in the relevant Hong Kong design guideline.

\section{Disciplines} \\ Engineering | Science and Technology Studies

\section{Publication Details} \\ Zhang, S., Yu, T. \& Chen, G. M. (2017). Reinforced concrete beams strengthened in flexure with near- \\ surface mounted (NSM) CFRP strips: Current status and research needs. Composites Part B: Engineering, \\ $13130-42$.
}


Abstract: The near-surface mounted (NSM) FRP strengthening technique has attracted

a School of Civil, Mining \& Environmental Engineering, Faculty of Engineering \& Information Sciences, University of Wollongong, Northfields Avenue, Wollongong, NSW 2522, Australia.

b School of Civil and Transportation Engineering, Guangdong University of Technology, Guangzhou 510006, China. worldwide attention as an effective alternative to the externally bonded (EB) FRP strengthening technique. In the NSM FRP strengthening method, grooves are first cut in the concrete cover of a concrete member for the FRP reinforcement to be inserted and embedded using an adhesive. The NSM FRP method has many advantages over the EB FRP method, including a higher bonding efficiency and a better protection of the FRP reinforcement. Existing experimental studies have shown that FRP strips owned a better bond efficiency compared with other section shapes (e.g. round bars and square bars), due to the fact that they had a larger perimeter-to-cross-sectional area ratio. This paper presents a state-of-the-art review, particularly on the flexural strengthening of RC beams with NSM CFRP strips. The observed failure modes in laboratory experiments of such FRP-strengthened RC beams are classified and the existing strength models are examined along with the failure mechanisms behind. The main knowledge gaps to be bridged in future studies are also identified. This review partially formed the basis of the development of design provisions on the NSM strengthening technique in the relevant Hong Kong design guideline.

Keywords: FRP, near-surface mounted (NSM), strip, RC beams 


\section{$34 \quad 1$ Introduction}

35 The externally bonded (EB) FRP method has become a prevailing technique over the last two 36 decades [e.g. 1-2] for the strengthening of existing reinforced concrete (RC) members. In the 37 past ten years, as a promising alternative to the EB FRP method, the near-surface mounted (NSM) FRP strengthening technique has attracted increasing worldwide attention [e.g. 3-5]. In the NSM FRP strengthening method, grooves are first cut in the concrete cover of RC members and FRP bars are then embedded into the grooves with an adhesive. FRP bars of various cross-sectional shapes can be used in the NSM FRP strengthening method, such as square, round, and rectangular bars (Fig. 1). The NSM FRP method owns many advantages over the EB FRP method, including a higher bonding efficiency and a better protection of the FRP reinforcement [e.g. 4].

De Lorenzis and Teng [4] provided a detailed and critical review of the research available to them at that time on the strengthening of concrete structures with NSM FRP reinforcement.

Their review covered various aspects of the NSM FRP strengthening technique (e.g. FRP reinforcement; construction aspects; bond) for various applications (e.g. flexural strengthening; shear strengthening). De Lorenzis and Teng [4] also outlined the main research needs for more extensive applications of this strengthening technique, with the bond behaviour between NSM FRP bars and concrete being identified as an important issue to be further examined. After De Lorenzis and Teng's work [4], a significant amount of research has been conducted, including experimental [e.g. 6-20], theoretical [e.g. 14, 15, 19, 21-29] and numerical [e.g. 9, 15, 30-32] studies into the behaviour of concrete structural members strengthened with various NSM FRPs. More recently, Coelho et al. [5] conducted a review on the bond behaviour of NSM FRP technique. Their review, however, was limited to the bond behavior of NSM FRP-to-concrete bonded interfaces and did not cover the behavior of NSM 
FRP-strengthened RC beams. In addition, Coelho et al.'s review [5] appears to be inadequate in the sense that (1) it did not cover some of the debonding failure modes reported in the existing literature [e.g. 7, 14, 19]; (2) it did not cover the recent advances in the development of bond-slip models [e.g. 26, 33] and bond strength models which are important for a better understanding of bond behaviour between NSM FRP and concrete.

One important finding by these more recent studies is that FRP strips (rectangular bars which have a large bar height-to-thickness ratio) are superior to NSM FRP bars of other shapes in terms of the bond performance [e.g. 5, 16, 19, 34, 35] and thus the strengthening efficiency [e.g. 3, 5]. This is due to the fact that an FRP strip usually has a larger perimeter-to-cross-sectional-area ratio and a larger embedment depth than an FRP bar of other shapes, which consequently leads to a larger bond force between NSM FRP and surrounding concrete and a higher utilization of the tensile capacity of FRP. Strips made of carbon FRP (CFRP) are more attractive than other types of FRP for NSM strengthening applications due to their high strength and stiffness which could lead to a small cross-sectional area. The recent studies on NSM CFRP strips-strengthened concrete structures have led to much improved understanding of and more rational theoretical models for such structures, especially for those where CFRP strips are used for flexural strengthening. These studies have also unpinned the first ever systematic design procedure for the NSM strengthening technique in a design guideline [36] for which the authors are among the main contributors. Against this background, this paper presents a state-of-the-art review on the flexural strengthening of RC beams with NSM CFRP strips. This review partially formed the basis of the development of design provisions on the NSM strengthening in the relevant Hong Kong design guideline [36]. 
 \\ 2 Behaviour and debonding failure modes of $\mathrm{RC}$ beams strengthened in}

85

86

87

\section{flexure with NSM FRP}

\subsection{General Behaviour of NSM FRP-Strengthened RC Beams}

Many laboratory tests on RC beams strengthened with NSM round FRP bars or square FRP bars have been conducted to investigate this promising technique [e.g. 3, 8, 37-41]. A significant number of experimental studies have also been conducted on RC beams strengthened in flexure with NSM CFRP strips (referred to as NSM CFRP RC beams hereafter for simplicity) in the past two decades [e.g. 3, 20, 42-56]. The existing experimental studies on NSM CFRP RC beams generally show a significant enhancement of the flexural capacity of the strengthened RC beam, with the maximum percentage increase in the flexural capacity being more than $200 \%$. The exact amount of enhancement depends on the amount of FRP, the steel reinforcement ratio and the failure mode, among others. Compared to the results of RC beams strengthened with externally bonded FRP plates (referred to as FRP-plated RC beams hereafter for simplicity), a much higher utilization of the tensile capacity of the FRP was observed in NSM CFRP RC beams [e.g. 3, 20, 44, 48, 50]. Furthermore, similar to the observation from bonded joint tests [e.g. 34, 35], NSM CFRP strips showed much higher bond efficiency than NSM FRP round bars in NSM CFRP RC beams [e.g. 3], owing to the higher perimeter-to-cross-sectional area ratio of the former.

From the load-deflection curves at the mid-span of most NSM CFRP RC beams, it was shown that NSM CFRP strips did not contribute much to the flexural stiffness of the beam in the elastic stage (i.e. before concrete cracking). After cracking, however, the flexural stiffness of the beam can be significantly increased compared with an un-strengthened beam. The flexural strength as well as the ductility of NSM CFRP RC beams was much higher than FRP-plated RC beams [e.g. 3, 44]. Using U-shaped FRP/steel jackets for end anchorage of 
109 NSM CFRP strips was shown to postpone the debonding failure of FRP and thus

110 significantly improve the ductility of the beam, although the increase in the flexural capacity

111 was not apparent [e.g. 50, 54, 57]. Information on the effect of U-shaped jacketing on the

112 effectiveness of NSM FRP used for flexural strengthening, however, is very limited.

\section{$113 \quad 2.2$ Debonding failure modes}

114 Despite a relatively strong bond between NSM CFRP strips and concrete, debonding failures

115 are still likely to happen in RC beams strengthened in flexure with NSM CFRP strips. In the

116 context of simply-supported NSM CFRP RC beams, debonding failure modes are likely to

117 occur both at the ends of NSM CFRP strips and in the maximum moment region. Apart from

118 interfacial debonding that occurs at or near a bi-material interface, debonding may also occur

119 in the form of separation of concrete cover where the concrete cover containing the NSM

120 CFRP strips are detached along the level of the steel tension bars. In this paper, the term

121 "debonding" refers to both interfacial debonding failure and cover separation failure; that is, it refers to all failure modes where the composite action between the FRP and the concrete beam is not maintained. In the experimental studies of NSM CFRP RC beams, in addition to the two conventional failure modes of RC beams, namely, flexural failure by crushing of compressive concrete [e.g. 47, 49, 58] and flexural failure by rupture of FRP [e.g. 3, 42], the following debonding failure modes have been reported: [e.g. 49, 50]. In this failure mode, the debonding of the CFRP strip starts from the maximum moment region and propagates to one of the FRP strip ends. A typical schematic diagram of the IC debonding failure is illustrated in Fig. 2. As can been seen from Fig. 2, the IC debonding failure can be further divided into two sub-types: IC interfacial debonding [50] and IC cover separation [49]. In the IC interfacial debonding, the debonding happens between the CFRP strip and the surrounding concrete (more 
accurately, in the thin concrete layer adjacent to the adhesive layer). In the IC cover separation failure, the CFRP strip together with the concrete cover is detached from the beam starting from the maximum moment region, with a major crack travelling on the plane of the steel tension bars; and

2) End debonding failure [e.g. 42-45, 51, 54, 59]. In this failure mode, the debonding of the CFRP strip starts from one end of the FRP strip and propagates to the mid-span of the beam. This failure mode is mainly due to the high interfacial shear and normal stresses

While the above failure modes were reported in the existing literature, some researchers only indicated that failure of the beam was caused by concrete cover separation but did not mention where the failure initiated [e.g. 48, 52]. Among the above debonding failure modes, cover separation (i.e. IC cover separation and end cover separation) has been found to be more common than interfacial debonding (i.e. IC interfacial debonding and end interfacial debonding) in NSM CFRP RC beams. Possible reasons for this phenomenon include: (1) the strong bond between NSM CFRP strips and concrete makes the interfacial debonding failure less likely; and (2) the large radial stresses, exerted by the steel tension bars to the surrounding concrete during their tension process [31], plays an important role in accelerating 
159 debonding is also an important debonding failure mode, especially for NSM

160 FRP-strengthened RC beams with a relatively large beam width [28]. The present paper aims

161 to clarify the failure mechanism of the above debonding failure modes, to summarize the

162 established strength models and to identify the gaps of knowledge for future research.

163

1643 IC debonding

165 Although IC interfacial debonding and IC cover separation are both termed as debonding 166 failure, the intrinsic failure mechanisms of them are quite different. The interfacial debonding

167 failure happens on the NSM CFRP strip-to-concrete interfaces and the debonding strength is

168 thus mainly controlled by the material and/or interfacial properties on/near such interfaces.

169 Obviously, in order to find out the debonding mechanism and establish strength models for

170 interfacial debonding failures in NSM CFRP RC beams, the fundamental issue is to expose

171 the bond behaviour of the NSM CFRP strip-to-concrete interface. In contrast, the cover

172 separation failure happens on the horizontal plane of tension steel bars with both concrete

173 cover and FRP detached from the RC beam. Therefore, in order to establish the strength

174 models for cover separation failures in NSM CFRP RC beams, one of the fundamental issues

175 is to clarify the failure mechanism on the horizontal plane of tension steel bars.

\section{$176 \quad 3.1$ IC Interfacial Debonding}

\section{3.1.1 Failure mechanism}

178 The failure process and mechanism of IC interfacial debonding is usually as follows: when a

179 dominating flexural crack occurs in/near the maximum moment zone, the tensile stress in the

180 concrete releases and is transferred onto the tension steel bars as well as FRP reinforcement

181 through interfacial shear stresses. Near the intersection of FRP reinforcement and the

182 dominating flexural crack, high local interfacial shear stresses happens as a result of the

183 geometric discontinuity of concrete due to the existence of the flexural crack. These high 
184 local interfacial shear stresses increase as the applied load increases and finally result in the

185 initiation of debonding between FRP and concrete while it reaches a critical level. Afterwards,

186 the IC interfacial debonding process is mainly driven by the opening of the flexural crack

187 which causes relatively displacements between FRP and concrete. The propagation of

188 debonding therefore strongly depends on the bond behaviour of NSM CFRP strip-to-concrete

189 interfaces, which can be investigated through the tests of NSM CFRP strip-to-concrete

190 bonded joints as shown in Fig. 4. In other words, the findings from such bonded joints has the

191 potential to be used for predicting the force (stress) that can be developed in the NSM CFRP

192 strip at IC interfacial debonding. In the following subsections, the existing studies on NSM

193 CFRP-concrete bonded joints/interfaces are first reviewed based on which recommendations

194 on the bond strength of IC interfacial debonding in an NSM CFRP RC beam are provided.

\section{3.1.2 Behaviour of NSM CFRP strip-to-concrete interfaces}

196 The interfacial bond behaviour has been commonly studied using pull-out tests on NSM

197 FRP-to-concrete bonded joints. By far, the beam pull-out test and the direct pull-out test have

198 been adopted by existing studies to study the bond behavior between NSM FRP bars and

199 concrete. The former one had been widely used for the study of the bond characteristics of 200 steel bars and was introduced by Nanni et al. [60] for NSM FRP bars. The later one has three 201 main sub-types: one-side pull-out test [e.g. 6, 21, 45, 61, two-side pull-out test [e.g. 62], and

202 C-shaped block pull-out test [e.g. 37, 38]. As the one-side pull-out test is the simplest one to 203 be implemented in laboratory experiments and its loading mechanism is direct and clear, it 204 has been the most common test method adopted by researchers.

Failure modes

207 A number of failure modes have been observed in experimental studies of NSM CFRP 208 strip-to-concrete bonded joints, including: (1) adhesion failure on the strip-to-adhesive 
interface $[18,19,58,61,63,54]$; (2) adhesion failure on the adhesive-to-concrete interface

$[14,18,19,34,35,64]$

(3) cohesion failure in a thin layer of concrete near the

211 adhesive-concrete interface $[6,7,14,18,19,21,63-66]$; (4) cohesion failure in the adhesive

212 [7, 16, 34, 61]; (5) splitting of the concrete block [7]; and (6) rupture of FRP strip [14, 18, 19].

213 Among these failure modes, the splitting of concrete block only happened in the specimens

214 where the CFRP strips were deliberately embedded much deep in concrete blocks [7]. This

215 failure mode is therefore unlikely to occur in RC beams as the embedment depth of FRP

216 strips in RC beams is generally limited by the thickness of concrete cover. The rupture of

217 FRP strip depends on the tensile strength of FRP and is thus not a property of the bonded

218 interface. The adhesion failure at strip-to-adhesive or adhesive-to-concrete interfaces is

219 largely a result of the poor surface condition at the corresponding interface (e.g. the surface of the CFRP strip or groove is not well cleaned) while the cohesion failure in the adhesive generally occurs when a weak adhesive is used or when the adhesive thickness is too small so that the stress concentration in the adhesive layer is significant. These three failure modes are not the desired failure modes as the failure occurs in the strengthening system and thus the strengthening efficiency would be significantly compromised. Indeed, these failure modes should be avoided in the design by a proper groove size, an appropriate treatment of the interfaces and selection of adhesives. Therefore, existing studies [4, 67] have suggested that the preferred failure mode is cohesion failure in a thin layer of the concrete near the adhesive-to-concrete interface. With such failure mode, the bond strength is governed largely by the concrete properties but not the properties on the adhesive-to-concrete interface or the CFRP-to-adhesive interface, so the development of a design theory is also easier. A few bond-slip and bond strength models have been proposed for this failure mode and are discussed later in this section. 
235 An accurate bond-slip model for the NSM CFRP strip-to-concrete interface is crucial to an

236 in-depth understanding of debonding failures in NSM FRP-strengthened RC members, and is

237 necessary for developing accurate bond strength models for NSM CFRP strip-to-concrete

238 interfaces. In addition, an accurate bond-slip model is critical to establishing accurate finite

239 element models of NSM FRP-strengthened RC members for predicting debonding processes.

240 Compared to bond-slip models developed for EB FRP laminate/plate-to-concrete interfaces

241 [e.g. 68, 69], existing work on bond-slip models for NSM FRP strip-to-concrete interfaces is

242 still relatively limited. Similar to EB FRP systems, the bond-slip model for NSM

243 FRP-to-concrete interfaces can be developed using experimental approaches (i.e., direct

244 regression of experimental results) [e.g. 21, 38, 70] or numerical parametric studies [e.g. 69].

245 When the experimental approach is adopted, the bond-slip model may be determined from axial strain distributions of the CFRP bar obtained by strain instruments [37] or from the average bond stress versus average slip (obtained from loaded-end slip and free-end slip) curve [e.g. 38]. The large scatter of test results as a result of the heterogeneity of concrete [4] may influence the accuracy of the proposed bond-slip curves. In addition, the bond behaviour on the FRP-to-adhesive interface might be interfered by the installation of strain gauges for the strain measurement. By far, four bond-slip models have been proposed by De Lorenzis and her co-workers [38, 71-73] for NSM FRP round bars-to-concrete interface based on the test results. However, these bond-slip models cannot be directly applied to NSM CFRP strip-to-concrete interfaces. The stress state in the adhesive and the surrounding concrete is relatively complicated for NSM FRP round bars than for NSM FRP strips especially when ribbed bars/spirally wounded bars are used. For NSM CFRP strip-to-concrete interface, a bond-slip model was proposed by Sena-Cruz and Barros [74], based on a model adopted for steel bar-to-concrete interfaces [75]; their model was calibrated with their tests in which the 
259 concrete was deliberately strengthened with steel fibres to avoid failure in the concrete. The

260 bond-slip model adopted by CEB-FIP [76] for steel bar-to-concrete interfaces was

261 recommended by Borchert and Zilch and the linear-softening bond-slip model which has the

262 same form as that for EB FRP-to-concrete interface was used by Seracino et al. [21] for NSM

263 CFRP strip-to-concrete interface. The validity of the above models is still uncertain in the

264 sense that they were based on previous work on steel bar-to-concrete interfaces or on EB FRP

265 reinforcements but not directly deduced from experimental tests or verified numerical

266 simulations. However, the proposals of these bond-slip models provide useful attempts and

267 help to some extent understand the bond behaviour of NSM CFRP strip-to-concrete interfaces.

268 More recently, using the verified 3-D meso-scale FE model proposed by Teng et al. [67, 77],

269 Zhang et al. [26] conducted a parametric study to examine the bond-slip relationship on NSM

270 CFRP strip-to-concrete interfaces. It was found from the study that: (1) the bond-slip curve

271 has a nonlinear ascending branch with the slope continuously decreasing; (2) the descending

272 branch is also nonlinear with the magnitude of the slope increasing first and then decreaseing

273 with the increase of slip; (3) the ascending and descending branches are smoothly connected.

274 Finally they proposed the bond-slip relationship (Eq. 1) for such bonded interfaces with the currently preferred failure mode (i.e. cohesion failure in the concrete near the

276 adhesive-concrete interface), in which the concrete cylinder strength $\left(f_{c}\right)$ and the groove

277 height $\left(h_{g}\right)$-to-width $\left(w_{g}\right)$ ratio were finally selected as the two key parameters that 278 influence the bond behaviour.

$$
\tau=A\left(\frac{2 B-s}{B}\right)^{2} \sin \left(\frac{\pi}{2} \cdot \frac{2 B-s}{B}\right) \quad \text { with } \quad s \leq 2 B
$$

281 where $\tau$ is the bond stress, $s$ is the slip, $A=0.72 \gamma^{0.138} f_{c}^{0.613}$ and $B=0.37 \gamma^{0.284} f_{c}^{0.006}$, 
$282 \gamma=\frac{h_{g}}{w_{g}}$ is the groove height to-width ratio and $f_{c}$ is the cylinder compressive strength of

concrete.

$\underline{\text { Bond strength models }}$

286

The bond strength is the ultimate tensile force that can be developed in the FRP reinforcement in a pull-out test before the debonding between FRP and concrete occurs. It has been found in existing studies [e.g. 6, 63] that the bond strength of NSM CFRP strip-to-concrete interface increases with when the bond length is relatively small, but when the bond length exceeds a threshold value, a further increase in the bond strength cannot be obtained from a further increase in the bond length. The threshold value of bond length has been referred to as the effective bond length $\left(L_{e}\right)[$ e.g. 78, 79]. The fracture mechanics-based approaches $[78,81]$ can well interpret the existence of an effective bond length and can be used to establish the bond strength based on a given bond-slip curve [80, 81]. By now, four bond strength models of NSM CFRP-to-concrete interfaces have been proposed for the currently preferred failure mode. They are introduced below.

299 Based on their test results, Seracino and co-workers [7, 21, 65] proposed a bond strength

300 model for cohesion failure in a thin layer of concrete near the adhesive-to-concrete interface

301 (referred to as debonding in Refs. [7], [21] and [65]). In this model, the bond strength $P_{u, s}$ of

302 NSM CFRP strip-to-concrete interface is expressed as

$$
P_{u, s}=\alpha_{p} 0.85 \beta_{e} \beta_{L, s} \gamma_{s}^{0.25} f_{c}^{0.33} \sqrt{E_{f} A_{f} L_{\text {failure }}\left(\frac{h_{f}+c_{a}}{c_{a}}\right)^{1.2}}
$$




$$
\alpha_{p}= \begin{cases}1 & \text { for the mean value } \\ 0.85 & \text { for the } 95 \% \text { lower bound }\end{cases}
$$

$$
\beta_{e}=0.283 \frac{a_{e}}{h_{f}}+0.196 \leq 1
$$

$$
\beta_{L, s}=\frac{L_{b}}{L_{e, s}} \leq 1
$$

$$
L_{e, s}=\frac{\pi}{2(0.802+0.078)} \sqrt{\frac{0.976 \gamma_{s}^{0.526} E_{f} A_{f}}{f_{c}^{0.6} L_{\text {failure }}}}
$$

309 where the reduction factor $\beta_{e}$ accounts for the effect of edge distance $a_{e}$ of concrete block

310 on the bond strength [65]; $\gamma_{s}$ is the height-to-width ratio of the failure contour [21] where

311 the height of contour is equal to CFRP strip height $h_{f}+1 \mathrm{~mm}$ and the width is equal to the

312 CFRP strip thickness $t_{f}+2 \mathrm{~mm} ; f_{c}$ is the cylinder compressive strength of concrete; $E_{f}$

313 is the elastic modulus of CFRP strip, $A_{f}$ is the cross-sectional area of the CFRP strip;

$314 L_{\text {failure }}=2 h_{f}+t_{f}+4 \mathrm{~mm}$ is the length of the failure contour; $c_{a}$ is the smallest distance

315 between the CFRP strip and the surface of the concrete [7]; reduction factor $\beta_{L, s}$ accounts

316 for the bond length of CFRP strip $L_{b}$ on the bond strength; and $L_{e, s}$ is the effective bond 317 length.

Oehlers et al.'s model [23]

320 Based on the model by Seracino and co-workers (Eq. 2), Oehlers et al. [23] proposed a bond 321 strength model for NSM FRP-to-concrete bonded joints containing several NSM CFRP 322 strips:

$$
P_{u, o}=\alpha_{p} 0.85 \beta_{e} \beta_{L, s} \gamma_{s}^{0.25} f_{c}^{0.33} L_{\text {failure }} \sqrt{n_{f} E_{f} A_{f}+k_{E A C} E_{c} A_{c}}
$$




$$
k_{E A C}=0.45-0.03\left(M_{u} / M_{c r}\right)
$$

325

326

331

where $n$ is the number of NSM FRP strips, $E_{c}$ is the elastic modulus of concrete, $A_{c}$ is the cross-sectional area encompassed by the failure plane, $k_{E A C}$ is a reduction factor for axial rigidity of concrete, $M_{u}$ is the applied moment at IC debonding (equal to zero for NSM FRP-to-concrete bonded joint ), and $M_{c r}$ is the moment at the initial cracking of the beam.

\section{Zhang et al.'s model [27]}

Zhang et al. [27] proposed another bond strength model, as expressed in Eq. 9. In this model, the effective bond length and the reduction factor accounting for the detrimental effect of an insufficient bond length were developed based on the bond-slip model proposed by Zhang et al. [26].

$$
\begin{gathered}
P_{u, z}=\beta_{L} \sqrt{2 G_{f} E_{f} A_{f} C_{\text {failure }}} \\
G_{f}=0.40 \gamma^{0.422} f_{c}^{0.619} \\
L_{e, z}=\frac{1.66}{\eta} \quad \text { where } \quad \eta^{2}=\frac{\tau_{\max }^{2} C_{\text {failure }}}{2 G_{f} E_{f} A_{f}} \\
\beta_{L, z}=\frac{L_{b}}{L_{e, z}}\left(2.08-1.08 \frac{L_{b}}{L_{e, z}}\right) \text { when } L_{b}<L_{e, z} \quad \text { and } \quad \beta_{L, z}=1 \quad \text { when } L_{b} \geq L_{e, z}
\end{gathered}
$$

where $L_{b}$ and $L_{e, z}$ are the bond length and effective bond length respectively; $G_{f}$ is the interfacial fracture energy between NSM CFRP strip and concrete; the cross-sectional contour of the failure surface $C_{\text {failure }}$ is equal to the sum of the three side lengths of the groove; and the reduction factor $\beta_{L, z}$ accounts for the detrimental effect of insufficient bond lengths on the bond strength.

\section{Bilotta et al.'s model [20]}


More recently, Bilotta et al. [20] proposed a bond strength model based on the regression of test results collected by them. This bond strength model is originally expressed in terms of maximum strain $\varepsilon_{\max }$ in the $\operatorname{FRP}($ Eq. 13).

$$
\varepsilon_{\max }=157 \frac{\left(C_{\text {failure }}\right)^{0.66}}{\left(E_{f} A_{f}\right)^{0.823}}
$$

The bond strength in terms of ultimate load can thus be obtained by multiplying Eq. 13 with $E_{f} A_{f}:$

$$
P_{u, b}=E_{f} A_{f} \varepsilon_{\max }=157\left(C_{\text {failure }}\right)^{0.66}\left(E_{f} A_{f}\right)^{0.177}
$$

\section{Discussion on bond strength models and future research needs}

Among the above existing bond strength models, Bilotta et al.'s model [20] appears most

inferior as it ignores the influence of both concrete strength and bond length on the bond strength. In Oehlers et al.'s model [23], the applied moment at IC debonding in a beam needs to be given first to calculate the reduction factor $k_{E A C}$, thus it is not a truly predictive model.

Furthermore, the influence of bond length on the bond strength is also not considered in this model. Comparison between Seracino and co-workers' model [7, 21, 65] and Zhang et al.'s model [27], which was reported in Ref. [27] making use of results of 51 test specimens collected from existing studies, revealed that both models provide close predictions for the test results when the bond length of the CFRP strip is sufficiently long (not smaller than the

364 effective bond length), but the model proposed by Zhang et al. [27] performs significantly

365 better than Seracino and co-workers' model [7, 21, 65] when the bond length is insufficient

366 (smaller than the effective bond length). This is mainly because that the effective bond length equation and the corresponding bond length reduction factor in the model proposed by Zhang 
model, while the effective bond length equation in the model by Seracino and co-workers [7, $21,65]$ is based on an assumed linear-softening bond-slip relationship and the bond length reduction factor is described using an assumed linear function.

373 It should be noted that the edge distance and the groove spacing have a significant effect on the bond strength, and their influences have not been fully studied. In the model by Seracino and co-workers [7, 21, 65], although a reduction factor accounting for the effect of edge distance was included, it was based on regression of only limited test results by them [65]. In Oehlers et al.'s model [23], although the involvement degree of the concrete encompassed by the failure plane could be reflected by the groove spacing, the effect of the groove spacing on the bond behavior of each FRP strip was still not considered. Some studies conducted by Barros and co-workers [e.g. 82-86] on RC beams strengthened in shear with NSM FRP strips can be referred to for considering the effect of groove spacing on the bond strength.

Considering that the failure modes of FRP strips NSM to concrete resemble those of adhesive anchors, Barros and co-workers develop a model which relates the bond strength of NSM FRP-concrete interface in shear-strengthened beams to the so-called "semiconical fracture surface of concrete" surrounding the NSM strip. The NSM FRP strip is thought to be pulled out when the principal tensile stress of concrete on this semiconical surface exceeds the tensile strength of concrete. The method is able to consider the effect of groove spacing (i.e., the "interaction among adjacent strips" in their papers) on the bond behaviour between NSM FRP strip and concrete: when the groove spacing is small, the semiconical fracture surfaces of adjacent NSM FRP strips overlap with each other and thus the total efficient/envelop fracture area becomes smaller than the direct summation of the semiconical fracture area of each NSM FRP strip. While this method has the potential to be extended to study the effect of groove spacing on the bond strength of bonded joints with multiple NSM FRP strips, future 
research is needed to develop a large experimental database on such bonded joints for verification/refinement of the method. It should be also noted that most existing studies on the bond behaviour between NSM FRP and concrete were based on ambient temperature. The effect of elevated temperature on the bond behaviour as well as the strengthening efficiency of NSM FRP strips have not been clarified, while preliminary studies have been carried out by researchers [e.g., 87-90]. Further studies are therefore needed to clarify the effects of edge distance, groove spacing and elevated temperature for more accurate bond-strength models.

\subsubsection{IC interfacial debonding strength model}

402 Vasquez and Seracino [24] directly used the bond strength mode proposed by Seracino and co-workers [7, 21, 65] (as expressed in Eq. 2) for NSM CFRP strip-to-concrete bonded joint to predict the force in the NSM FRP strip at IC debonding in NSM CFRP RC beams.

405 Vasquez and Seracino [24] assessed this model (Eq. 2) using results of NSM CFRP RC beams collected from existing studies and found that the prediction-to-test ratio is 0.88 . This conservative prediction is mainly because that in $\mathrm{RC}$ beams there usually exist more than one major flexural cracks and the debonding force in the FRP between two adjacent cracks is

409 larger than that in one-side pull out test of the corresponding bonded joints, as has been

410 proved by Teng et al. [91] by using an analytical solution in an EB FRP-to-concrete bonded

411 joint. Although the above method cannot be much criticized considering that this bond

412 strength on NSM CFRP strip-to-concrete interfaces generally offers a lower bound to the IC

413 interfacial debonding strength of RC beams (thus provide a conservative prediction for design

414 purpose), a more accurate design model which can take into count the influence of

415 multi-cracks still needs to be pursued.

417 It can be expected that the bond strength model proposed by Zhang et al. [27] provides 418 similar prediction of IC debonding strength to that by Seracino and co-workers [7, 21, 65], in 
419 the sense that in RC beams the bond length of FRP is normally larger than the effective bond

420 length. The difference between the bond strength model by Zhang et al. [27] and that by

421 Seracino and co-workers [7, 21, 65] may only be reflected in situations where the bond length

422 of NSM FRP is limited, such as in the shear strengthening of RC beams.

\section{$423 \quad 3.2$ IC Cover separation}

424 The failure process and mechanism of IC cover separation is as follows: the transfer of the tensile stress from the cracked concrete onto the tension steel bars after the formation of a dominating flexural crack incurs high local interfacial shear stresses near the intersection of tension steel bars and the dominating flexural crack. Besides, as the steel bars are usually not smooth but have some ribs on it, the relative displacement between steel bars and concrete also incurs radial stresses onto the surrounding concrete as shown in Fig. 5. These high local interfacial shear stresses and radial stresses increase with the applied load and finally induce separation failure on the plane of the tension steel bars. Due to their different failure mechanisms, the bond strength of NSM CFRP strip-to-concrete interfaces cannot be used in predicting the strength of IC cover separation in NSM CFRP RC beams.

By far, although IC cover separation failure has been observed in experimental tests, it has not yet attracted enough research attention. There has been no established strength model for IC cover separation failure, probably because its failure mechanism is relatively complicated. As mentioned earlier, the failure happens on the horizontal plane of tension steel bars, and at this failure plane, the clear concrete width is smaller than the beam width because of the existence of the steel bars. In addition, radial stresses exerted by the steel tension bars to the

441 surrounding concrete when the slip between the concrete and the steel tension bar develop 442 have found to further weaken the critical plane [30, 31]. An FE model taking into account the 443 above effects has been developed for establishing strength models for end cover separation in 
444 EB/NSM FRP-strengthened RC beams [31] but has not yet been extended to study IC cover

445 separation. Further studies are needed to develop strength models for IC cover separation.

4474 End debonding

448 End debonidng failure mode also contains two sub-types: end interfacial debonding and end

449 cover separation. Similar to IC debonding, these two sub-types of failure were controlled by

450 different failure mechanisms and should be treated separately. Although more and more attentions have been drawn to the development of end debonding strength models in NSM CFRP RC beams, the existing models have been still relatively limited.

\subsection{End Interfacial Debonding}

\subsubsection{Failure mechanism}

When the FRP-strengthened beam is under loading, high interfacial shear and normal stresses develop near the end of NSM CFRP strip as a result of the abrupt termination of the strip [e.g. $25,29]$. Due to the high interfacial stresses, an inclined crack usually occurs near the end of the NSM FRP, and another flexural-shear crack usually appears in the bonded region of FRP at a certain distance (i.e. the crack spacing) as shown in Fig. 3a. These interfacial stresses

460 increase with the applied load and finally induce the debonding between FRP and concrete.

\subsubsection{Strength models}

462 Two strength models have been established for end interfacial debonding failure. The first one is proposed by Hassan and Rizkalla [42] based on interfacial stresses between NSM CFRP strip and concrete, and the other one is originally proposed by Oehlers et al. [92, 93] for FRP-plated RC beams and modified by Vasquez and Seracino [24] for NSM CFRP RC

466 beams. It should be noted that existing strength models of end debonding for FRP-plated RC

467 beams are generally not applicable to NSM CFRP RC beams, because some parameters in 
these models were calibrated using test results of FRP-plated RC beams [94]. The two existing strength models are introduced in details here followed by a discussion of these two models.

\section{Hassan and Rizkalla's model [42]}

473 For end interfacial debonding failure, Hassan and Rizkalla [42] proposed an approach for predicting the strength of NSM CFRP RC beams. Based on the interfacial stress analysis of Malek et al. [95] for EB FRP systems, Hassan and Rizkalla [42] gave closed-form expressions to predict the interfacial shear stress $\tau$ between NSM CFRP strip and concrete, as expressed in Eqs. 15 and 16 respectively for a simply-supported beam subjected to a point load and a simply-supported beam subjected to two symmetric point loads:

$$
\begin{aligned}
& \tau=\frac{t_{f}}{2}\left[\frac{n_{f} P a y_{\text {eff }}}{2 I_{\text {eff }}} \omega e^{-\omega x}+\frac{n_{f} P y_{\text {eff }}}{2 I_{\text {eff }}}\right] \\
& \tau=\frac{t_{f}}{2}\left[\frac{n_{f} P y_{\text {eff }}}{I_{\text {eff }}}+\frac{n_{f} P y_{\text {eff }} a}{I_{\text {eff }}} \omega e^{-\omega x}\right]
\end{aligned}
$$

$$
\omega^{2}=\frac{2 G_{a}}{t_{a} t_{f} E_{f}}
$$

482 where $x$ is the horizontal distance from the strip end, $t_{f}$ is the thickness of the CFRP strip,

$483 n_{f}=E_{f} / E_{c}$ is the modulus ratio between FRP and concrete, $P$ is the point load, $y_{\text {eff }}$ is the 484 distance from the strip centroid to the neutral axis of the section, $a$ is the distance from the 485 strip end to the nearest support; $I_{\text {eff }}$ is the effective moment of inertia and is expressed in Eq. $48618, e$ is the base of the natural algorithm, and $G_{a}$ and $t_{a}$ are the shear modulus and 487 thickness of the adhesive respectively, 


$$
I_{e f f}=\left(\frac{M_{c r}}{M_{a}}\right)^{3} I_{g}+\left(1-\left(\frac{M_{c r}}{M_{a}}\right)^{3}\right) I_{c r}
$$

where $M_{c r}$ and $M_{a}$ are the cracking and applied moments on a beam section respectively,

$490 \quad I_{g}$ is the transformed gross moment of inertia in terms of concrete of the strengthened

491 section, and $I_{c r}$ is the transformed moment of inertia in terms of concrete of the cracked 492 section.

493

494 Obviously, the interfacial stresses obtained from Eqs. 15 and 16 peak when $x=0$, indicating 495 that the cut-off point is the critical location for the initiation of debonding failure. By introducing the Mohr-Coulomb failure criterion, the interfacial stress $\tau_{\max }$ at failure can be expressed as

$$
\tau_{\max }=\frac{f_{c} f_{t}}{f_{c}+f_{t}}
$$

where $f_{c}$ and $f_{t}$ are the cylinder compressive strength and tensile strength of concrete respectively.

502 Substituting Eq. 19 into Eq. 15 or Eq. 16 with $x=0$ yields the applied load at end debonding failure of the strengthened beam.

\section{Oehlers et al.'s model [92, 93]}

506 Oehlers et al. [92, 93] referred to end debonding failures with the end of the EB FRP plate

507 located in the shear span as the Critical Diagonal Crack (CDC) debonding. Based on Zhang's method [96] for determining the shear strength of RC beams, Oehlers et al. [92, 93] proposed 
511 causing the diagonal crack (Eq. 20) and the shear force $V_{\text {slide }}$ causing the sliding of the

512 diagonal crack (Eq. 21). CDC debonding failure is assumed to occur when these two shear

513 forces become equal to each other.

$$
V_{\text {crack }} a_{v}=\left(x_{d}^{2}+h^{2}\right)\left(\frac{b f_{\text {tef }}}{2}+\frac{f_{t} n_{f} A_{f}}{h}\right)+F_{p s} h_{p s}
$$

$$
V_{\text {slide }}=0.4 f_{c} b h\left(1+2 \frac{F_{p s}+P_{\text {axial }}}{f_{c} b h}\right)\left(\sqrt{1+\left(\frac{x_{d}}{h}\right)^{2}}-\frac{x_{d}}{h}\right) f_{1} f_{2} f_{3}
$$

$$
f_{1}=\frac{3.5}{\sqrt{f_{c}}}
$$

$$
f_{2}=0.27\left(1+\frac{31.6}{\sqrt{h}}\right)
$$

$$
f_{3}=15 \frac{A_{s}}{b h_{0}}+0.58
$$

519 where $f_{\text {tef }}=0.156\left(f_{c}\right)^{2 / 3}\left(\frac{h}{100}\right)^{-0.3}$ and $f_{t}$ are the the effective tensile strength and tensile

520 strength of concrete respectively, $a_{v}$ is the shear span of the beam, $x_{d}$ is the horizontal

521 distance between the bottom position of the diagonal crack and the applied concentrated load, $h$ is the beam height, $A_{f}$ is the cross-sectional area of FRP, $P_{\text {axial }}$ is the maximum axial

523 force in the FRP, $F_{p s}$ is the tendon prestressing force, $h_{p s}$ is the depth of the tendon prestressing force position, and $f_{1}, f_{2}$ and $f_{3}$ are functions of concrete strength, beam height and tension reinforcement ratio respectively.

527 For FRP-plated RC beams, the value of $P_{\text {axial }}$ can be calculated using the bond strength model proposed by Chen and Teng [78], as recommended by Oehlers et al. [92, 93]. To make 
this model applicable to NSM CFRP RC beams, Vasquez and Seracino [24] recommended

530 that the value of $P_{\text {axial }}$ can be predicted by the bond strength model proposed by Seracino et

531 al. [21] for NSM CFRP strip-to-concrete interface.

532

533

534

535

536

537

538

539

540

541

542

543

544

545

546

547

548

549

550

551

552

553

\subsubsection{Discussions and future research needs}

Hassan and Rizkalla' model [42] offered a valuable pioneering study on end debonding strength models in RC beams strengthened with NSM CFRP strips. In this model, however, only the longitudinal shear stress is taken into account to determine whether debonding failure occurs, which to some extent lacks rigor. Vasquez and Seracino [24] assessed this model and found that the model was significantly conservative. This implies that the local failure in the concrete layer at the end of the FRP strip does not mean the debonding failure of the beam. As indicated by Vasquez and Seracino [24], Oehlers et al.'s model [92, 93] may be overly conservative, because the contribution of stirrups was not taken into account. The omission of the contribution of stirrups may be acceptable for FRP-plated RC beams but not reasonable for NSM CFRP RC beams. This is because that the debonding strain in the NSM FRP strip is usually larger than that in EB FRP plate, thus a higher strain in stirrup can be possibly developed. A comparison made by Vasquez and Seracino [24] showed that Oehlers et al.'s model $[92,93]$ gave an average prediction-to-test ratio of 0.74 for the collected specimens.

Obviously, the existing strength models for end interfacial debonding are quite limited. The interfacial stress based model [42] usually underestimates the debonding strength of the beam. The local failure in the concrete at the end of NSM CFRP strip cannot be treated as the debonding failure of the strengthened RC beam, as cracks on the tension surface of the beam makes interfacial stress redistribute before debonding failure. The prestress beam model [92, 93] ignores the contribution of the stirrups, which is not reasonable in RC beams 
554 strengthened with NSM CFRP strips. In fact, the "concrete tooth model", which has been

555 used in the establishment of end debonidng strength models in steel/FRP-plated RC beams

556 [e.g. 97, 98], is worth studying as the description of the failure mechanism is clear and is

557 similar to the observation in tests. Unfortunately, however, no such attempt has been carried

558 out in establishing strength models of end interfacial debonding in RC beams strengthened

559 with NSM CFRP strips.

$560 \quad 4.2$ End cover separation

561

562

563

564

565

566

567

568

569

570

571

572

573

574

575

576

577

578

\subsubsection{Failure mechanism}

Similar to end interfacial debonding, due to high interfacial stresses developed near the end of NSM FRP strips [e.g. 25, 29], an inclined crack first occurs near the end of the NSM FRP, and then another flexural-shear crack appears in the bonded region of FRP at a certain distance (i.e. the crack spacing) as shown in Fig. 3b. When these cracks further develop and intersect with the steel tension bars, the concrete cover between the two cracks forms a "tooth" whose top is dragged by the NSM CFRP strip in the shear direction. The concrete near the intersection of the tension steel bar and the inclined crack near the end of the NSM FRP (Point A in Fig. 3b) is subjected to a combined effect of the following aspects: (1) the tensile stress induced by the bending moment as a result of the drag force on the top of the "tooth"; (2) the shear stress induced by the drag force on the top of the "tooth"; (3) the clear concrete width is smaller than the beam due to the existence of the steel bars; and (4) more importantly, radial stresses (as shown in Fig. 5) may be generated by the steel tension bars onto the surrounding concrete when slips between the concrete and the steel occur. Therefore, the plane of the tension steel bars becomes the critical plane and a major crack forms on this plane when the tensile and shear stress on this place reaches a critical level. This major crack travels along the steel bar from the end of the NSM CFRP strip to mid-span of the beam as the applied load goes up, as shown in Fig. $3 b$. 
579

580

581

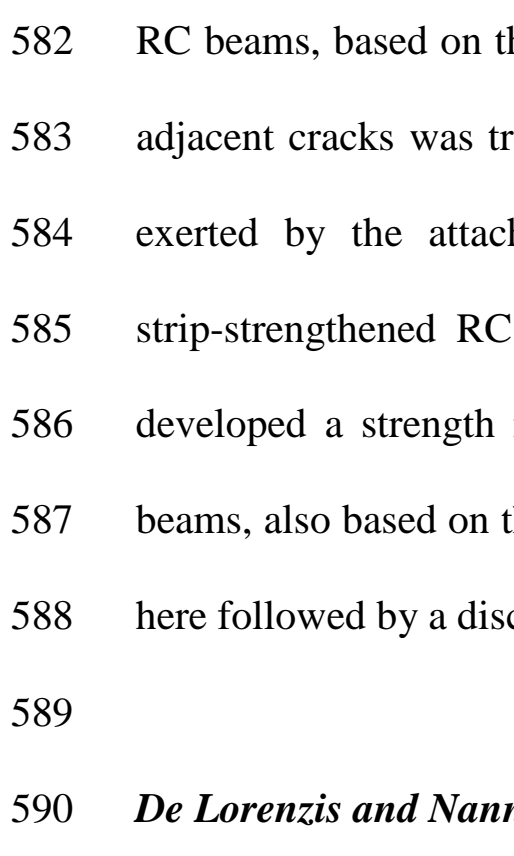

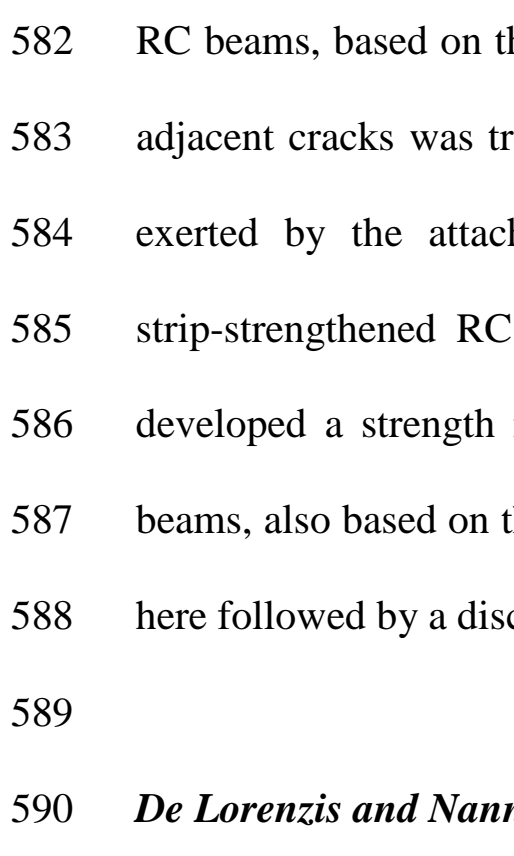

582 RC beams, based on the
583 adjacent cracks was treat
584 exerted by the attach
585 strip-strengthened RC
586 developed a strength
587 beams, also based on the followed by a discus
588 De Lorenzis and Nanni's
589 here
590

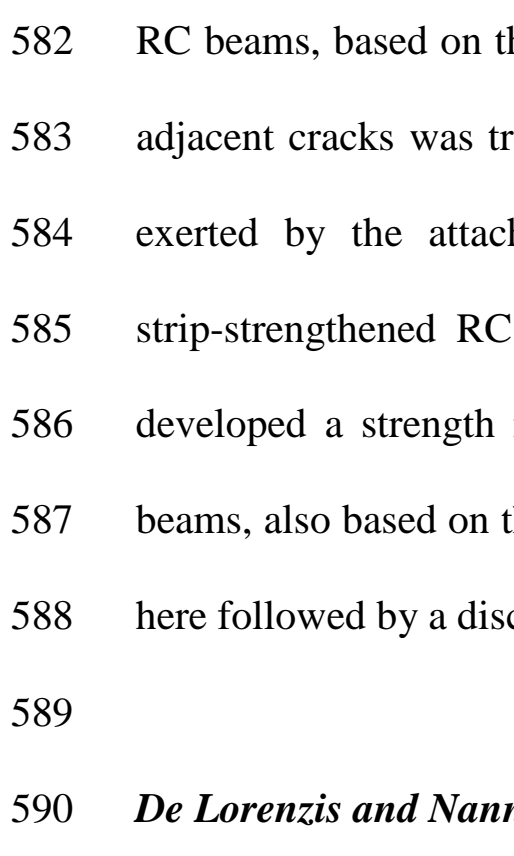

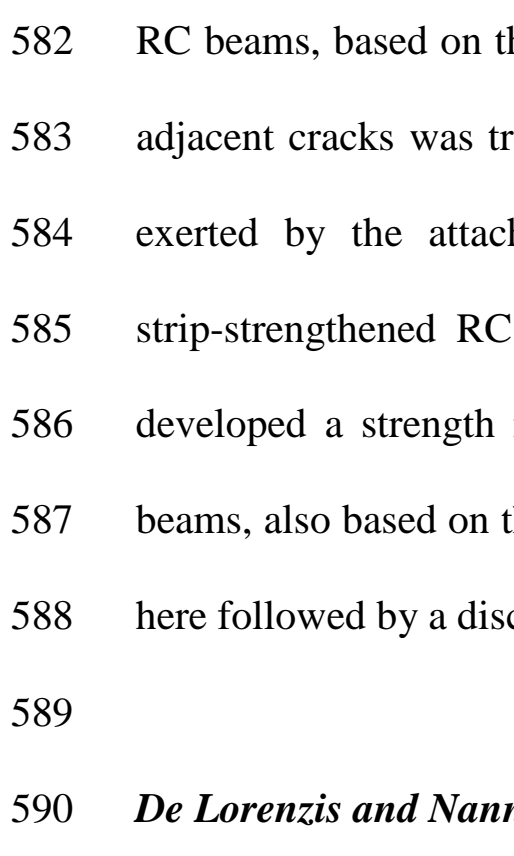

582 RC beams, based on the
583 adjacent cracks was treat
584 exerted by the attach
585 strip-strengthened RC
586 developed a strength
587 beams, also based on the followed by a discus
588 De Lorenzis and Nanni's
589 here
590

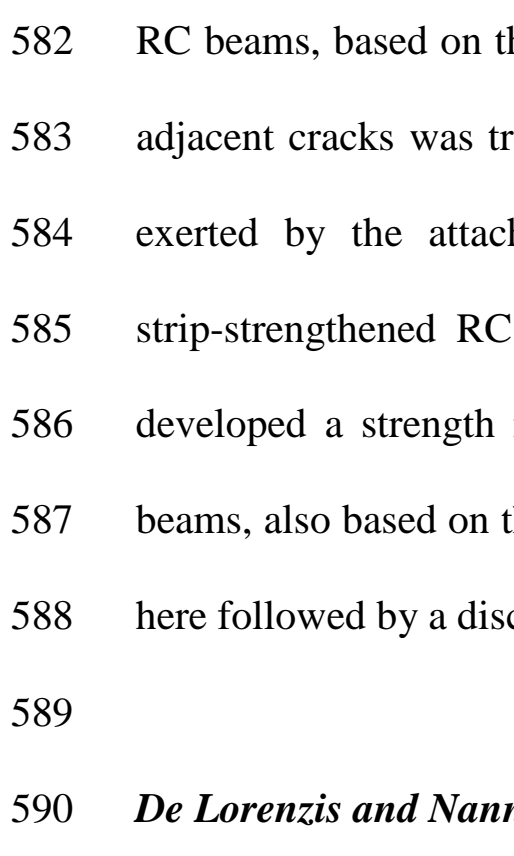

582 RC beams, based on the
583 adjacent cracks was treat
584 exerted by the attach
585 strip-strengthened RC
586 developed a strength
587 beams, also based on the followed by a disc
588 here Lorenzis and Nann
589 .
590 De L

582 RC beams, based on the
583 adjacent cracks was treat
584 exerted by the attach
585 strip-strengthened RC
586 developed a strength
587 beams, also based on the followed by a discus
588 De Lorenzis and Nanni's
589 here
590

591

592

593

594

595

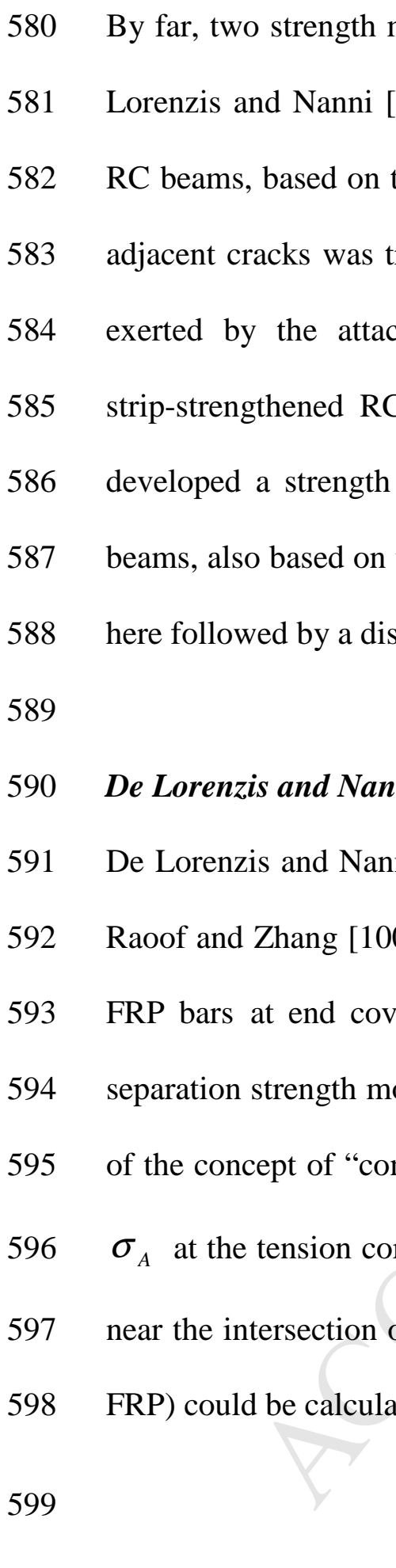

597

598

where $M_{A}=\tau n \pi d_{b} l h^{\prime}$ is the bending moment at the root of the concrete tooth, $I_{A}=b l^{3} / 12$

601 is the sectional moment of inertia of the concrete tooth, $l$ is the minimum crack spacing

$602 l_{\min }$ or maximum crack spacing $l_{\max }=2 l_{\min }, h^{\prime}$ is the vertical distance from the root of the 
concrete tooth to the centroid of NSM FRP, $b$ is the beam width, $d_{b}$ and $n$ are the

604 diameter and number of the FRP round bars respectively, and $\tau$ is the shear bond stress between NSM FRP bar and concrete. By assuming that failure of the beam occurs when the

606 stress $\sigma_{A}$ is equal to the tensile strength of concrete $f_{t}$, the shear bond stress $\tau_{\text {failure }}$ at

607 failure can be expressed as

608

$$
\tau_{\text {failure }}=\frac{f_{t} l}{6 h^{\prime}} \frac{b}{n \pi d_{b}}
$$

609 The shear stress should be equilibrated by the FRP axial stress. At the critical section (such as 610 the section corresponding to the loading points), the critical FRP axial stress can be 611 calculated as

$$
\sigma_{\text {failure }}=\frac{4 \tau_{\text {failure }} L_{p}}{d_{b}}
$$

613 where $L_{p}$ is the effective length of the NSM FRP bar in the shear span within which the

614 interfacial stress is assumed to be uniformly distributed. The value of $L_{p}$ was determined by 615 these authors to be the smaller one of $L_{p 1}$ and $L_{p 2}$, where $L_{p 1}$ is the length of the NSM 616 FRP bar in the shear span and $L_{p 2}$ is the equivalent length given by

$$
L_{p 2}=\left\{\begin{array}{lll}
1.86 l_{\mathrm{min}}^{2}-127 l_{\mathrm{min}}+2436 & \text { if } & l_{\min } \leq 50 \mathrm{~mm} \\
736 & \text { if } & l_{\min }>50 \mathrm{~mm}
\end{array}\right.
$$

618 where the minimum crack spacing $l_{\min }$ can be calculated as

$$
l_{\min }=\frac{A_{e} f_{t}}{u_{s} \sum O_{s}+u_{f} \sum O_{f}}
$$

620 where $A_{e}$ is the area of concrete in tension and is assumed to be product of the beam width 621 and twice of the distance from the centroid of steel tension bars to the soffit of the beam, $f_{t}=0.36 \sqrt{f_{c u}}$ is the tensile strength of concrete, $f_{c u}$ is the cube compressive strength of 
623 concrete, $\sum O_{s}$ is the total perimeter of the steel tension bars, $\sum O_{f}$ is the total perimeter of

624 the NSM FRP round bars, $u_{s}=0.28 \sqrt{f_{c u}}$ is the average local bond strength between steel

625 bars and concrete, and $u_{f}$ is the average bond strength between NSM FRP bars and concrete

626 and was recommended by De Lorenzis and Nanni [99] to be the local bond strength.

627

628 In order to apply the above model to NSM CFRP RC beams, the following modifications 629 need to be made: (1) the bending moment $M_{A}$ at the root of the concrete tooth should be

630 calculated based on the geometry of NSM CFRP strips; (2) the effective length $L_{p}$ should

631 be recalibrated using test results of NSM CFRP strip-strengthened RC beams ; and (3) the

632 average bond strength between NSM FRP bars and concrete $u_{f}$ should be calibrated using

633 bond strength model of NSM CFRP strip-to-concrete interface.

634

635

\section{Al-Mahmoud et al.'s model [9]}

636 The model proposed by Al-Mahmoud et al. [9] is quite similar to that proposed by De

637 Lorenzis and Nanni [99]. In this model, the bending moment $M_{A}$ at the root of the concrete

638 tooth is related to the FRP axial stress at the left cracked section (if the FRP is terminated on

639 the right) as

640

$$
M_{A}=\sigma_{f} A_{f} h^{\prime}
$$

641 The axial stresses in the FRP at the left cracked section can therefore be calculated as

$$
\sigma_{f}=\frac{M_{A}}{A_{f} h^{\prime}}=\frac{b l^{2}}{6 A_{f} d_{b}}
$$

$643 \sigma_{f}$ can also be expressed in terms of the bending moment $M_{l}$ of the strengthened beam at 644 the left cracked section as 


$$
\sigma_{f}=n_{f}\left(\frac{d_{f}-y_{0}}{I_{c r}}\right) M_{l}
$$

646 With the assumption that the end cover separation happens as the tensile stress in the concrete 647 at the tension corner near the root of the concrete tooth (i.e. Point A in Fig. 3b), combining 648 Eqs. 31 and 32 gives the following equation for calculating the bending moment of the 649 strengthened beam at the left cracked section at debonding failure:

$$
M_{l}=\frac{f_{t} I_{c r} b l^{2}}{6 n_{f} A_{f} d_{b}\left(d_{f}-y_{0}\right)}
$$

651 Where $I_{c r}$ is the transformed moment of inertia in terms of concrete of the cracked section, $d_{f}$ is the vertical distance from the centroid of the NSM FRP to the top surface (in compression) of the beam, and $y_{0}$ is the vertical distance from the neutral axis of the cracked section to the top surface of the beam.

655

\section{Teng et al.'s model [28]}

657 The model developed by Teng et al. [28] to predict the end cover separation strength of NSM

658 CFRP RC beams is based on the following idea: if the FRP strain on the left crack section 659 (Point B in Fig. 6) at end cover separation failure is known, the bending moment on the corresponding section can be obtained through a section analysis, and the ultimate load can

661 then be easily calculated by dividing the bending moment by the horizontal distance from the

662 left crack section to the nearest support. To obtain the strain in the FRP at the left cracked 663 section at failure (Point B in Fig. 6), the simplified FE model proposed by Zhang and Teng 664 [32] was adopted in Teng et al. [28]. In this FE model, the part of the RC beam between the two cracks near the FRP end was isolated from the beam (Fig. 6), the bending moments acting on the two cracked sections was realized through the external loads as shown in Fig. 6, and the plane section assumption was achieved using a rigid plate attached to each cracked 
668

669

670

671

672

673

674

675

676

677

678

679

680

681

682

683

684

685

686

687

688

section. Furthermore, the radial stresses exerted by the tension steel bars onto the surrounding concrete were modelled using a proposed cohesive-element-pair (CEP). The plane section assumption may not be exactly valid here, but it can simplify the FE model and may not introduce substantial errors. An equation for the FRP strain at the left cracked section at end cover separation failure was then developed through the regression of results of a numerical parametric study using the abovementioned simplified FE model:

$$
\begin{array}{r}
\mathcal{E}_{d b}=10^{4} \times \beta_{c s} \beta_{A E} \beta_{b o d} b_{\text {clear }} \sqrt{f_{c}} \\
\beta_{c s}=\left(\frac{4.5}{s_{c}^{0.3}}-\frac{c}{s_{c}}\right)\left(\frac{s_{c}}{100}-0.1\right)
\end{array}
$$

$$
\beta_{A E}=\frac{1}{\left(A_{f} E_{f}\right)^{0.9}}
$$

$$
\beta_{\text {bod }}=\left(\frac{b_{\text {clear }}}{D_{t}}\right)^{0.1}
$$

where $\beta_{c s}$ is a factor accounting for the combined effect of $s_{c}$ (crack spacing, in $\mathrm{mm}$ ) and $c_{d}$ (distance from the centroid of steel bars to that of FRP reinforcements, in $\mathrm{mm}$ ) on the failure strain; $\beta_{A E}$ is a factor accounting for the effect of axial stiffness of FRP strip $A_{f} E_{f}$ ( $A_{f}$ in $\mathrm{mm}^{2}$ and $E_{f}$ in $\mathrm{GPa}$ ); and $\beta_{b o d}$ is a factor accounting for the effect of ratio between the clear concrete width $b_{\text {clear }}$ (in $\mathrm{mm}$ ) and the sum of steel tension bar diameters $\mathrm{D}_{t}$ (in $\mathrm{mm}$ ). The cylinder compressive strength of concrete $f_{c}$ is given in $M P a$.

The value of the cracking spacing influences the FRP strain at the left cracked section at failure and the distance from the left cracked section to the nearest support. In Teng et al.'s model [28], the adopted model for minimum crack spacing $s_{c}^{\min }$ is also the one proposed by Zhang et al. [97], as expressed in Eq. 29 with $u_{f}=0.28 \sqrt{f_{c u}}$. According to Zhang et al. [97], 
the possible crack spacing value should be in the range from $s_{c}^{\min }$ to $2 s_{c}^{\min }$.

690

691

692

693

694

695

696

697

698

699

700

701

702

703

704

705

706

707

708

709

710

711

712

\subsubsection{Discussions and future research needs}

As De Lorenzis and Nanni's model [99] was originally proposed for NSM FRP round bar-strengthened RC beams, modifications should be made first to satisfy the geometric and mechanical properties of NSM CFRP strips. By now, however, the effective length $L_{p}$ and the average bond strength $u_{f}$ have not been calibrated by the authors or other researchers using test results of NSM FRP strip-strengthened RC beams, thus it cannot yet be used for predicting the cover separation strength in such FRP-strengthened RC beams. Both De Lorenzis and Nanni's model [99] and Al-Mahmoud et al. 's model [9] only took account for the tensile stress induced by the bending moment as a result of the drag force on the top of the "tooth" but not the shear stress induced at the same time. Furthermore, the weakness of the beam by the tension steel bars and the radial stresses were not considered in these two strength models. Teng et al.'s model [28] was based on results of the parametric study using an FE model which reflected all the above mentioned influencing factors. The performance of Teng et al.'s model [28], however, is significantly influenced by the accuracy of the model of crack spacing which is usually in a range from $s_{c}^{\min }$ to $2 s_{c}^{\min }$. Teng et al. [28] compared the predictions of their model with collected test specimens, with the crack spacing being the minimum stabilized value $s_{c}^{\min }$, the maximum stabilized value $2 s_{c}^{\min }$, and an intermediate value $1.5 s_{c}^{\text {min }}$ respectively to examine the effect of crack spacing. It was found that the predictions of Teng et al.'s model [28] with crack spacings of $1.5 s_{c}^{\min }$ and $2 s_{c}^{\min }$ led to average prediction-to-test ratios of 1.10 and 1.17 respectively; their standard deviations (STDs) were 0.119 and 0.172 and their coefficient of variations (CoVs) were 0.108 and 0.147 respectively. These statistics were much better than predictions of Teng et al.'s model [28] obtained with a crack spacing of $s_{c}^{\min }$ whose average prediction-to-test ratio, STD and CoV 
are $0.863,0.155$ and 0.180 respectively. Nevertheless, the model by Teng et al. [28] with any of the above three values of crack spacing offered much closer predictions to the test results than the model Al-Mahmoud et al. [9], the predictions of which were un-conservative, with the average prediction-to-test ratio, STD and CoV being 1.90, 1.34 and 0.702 respectively.

\subsection{Anchorage Measures for Preventing End Debonding}

719 In design, if debonding cannot be eliminated, IC debonding is preferable to end debonding because the latter usually happens in a brittle manner without any noticeable early warning. By now, metallic and non-metallic anchorage measures have been investigated in experimental tests for preventing/mitigating end debonding in $\mathrm{RC}$ beams strengthened in flexure with an EB FRP/steel plate. The metallic anchorage measures, in the form of steel bolts, steel clamps or steel U-jackets, were initially proposed for preventing end debonding in steel-plated RC beams [e.g. 101, 102]. The metallic anchorage measures, however, suffer from the following two disadvantages: the difficulty of installation and the poor resistance to corrosion. Therefore, non-metallic anchorage measures (such as FRP-based anchorage measures) are more attractive than metallic anchorage measures in FRP-strengthened RC beams for preventing end debonding. A number of studies have been conducted to explore the effectiveness of FRP U-jackets in preventing/mitigating end debonding failure in FRP-plated RC beams [e.g. 103-108], while the studies on the use of FRP U-jackets as anchorage measures for NSM FRP bars in NSM FRP-strengthened RC beams have been rather limited. These limited existing studies, however, have revealed that FRP U-jackets are quite effective in both postponing the end debonding of the beam and enhancing the ductility of the beam [50, 57, 109]. Before a reliable and economical design procedure for FRP U-jackets can be established for confident use in practice, future research should be conducted to address the following issues: (1) more experimental studies on the use of FRP 
U-jackets as the end anchorage measure of NSM FRP reinforcement should be conducted to provide a larger database; (2) the effect of the angle of FRP U-jackets inclined with respect to

740 the beam axis on the effectiveness of preventing end debonding in NSM FRP-strengthened

741 RC beams needs to be clarified; (3) the effect of termination position of NSM FRP

742 reinforcement (resulting in different section moment-shear force combination at the FRP end)

743 on the performance of FRP U-jackets in preventing/mitigating end debonding failure in NSM

744 FRP-strengthened RC beams needs to be studied; and (4) reliable FE approaches need to be established for a reliable design procedure for FRP U-jackets as end anchorage measures.

\section{Concluding remarks}

This paper has presented a critical review of the existing knowledge on NSM CFRP strips for flexural strengthening of $\mathrm{RC}$ beams. This review has been focused on the debonding failure modes in such FRP-strengthened RC beams, the mechanisms behind, and the corresponding strength models. The following conclusions can be made from the review:

1) The NSM FRP strengthening method is much more efficient than the EB FRP method in the flexural strengthening of RC beams, and NSM CFRP strips are superior to NSM FRP bars of other sectional forms (such as round bars and square bars) due to a larger

2) The desired debonding failure mode at the NSM FRP-to-concrete interface is the cohesion failure in a thin layer of concrete near the adhesive-to-concrete interface. This failure model can be achieved if the surfaces of concrete and CFRP are appropriately treated and a proper adhesive is used; 
761

762

763

764

765

766

767

768

769

770

771

772

773

774

775

776

777

778

779

780

781

782

783

784

785

3) Several local bond-slip models and bond strength models have been proposed for NSM CFRP strips-to-concrete interfaces. Some of them can now provide accurate predictions for single NSM FRP strip-to-concrete joints with sufficient concrete edge distances;

4) A number of experimental studies have been conducted on NSM CFRP RC beams, which have led to the identification of four debonding failure modes. Concrete cover separation has been found to be more often than interfacial debonding in NSM CFRP RC beams.

The review presented in this paper also suggests that the existing research is still very limited and the major gaps which need to be addressed by future research include:

1) There is a lack of experimental tests with sophisticated instrumentation which is necessary to thoroughly demonstrate the validity the existing bond-slip models for NSM CFRP strip-to-concrete bonded joints;

2) There is a lack of understanding on the effect of the concrete edge distance, the groove spacing and elevated temperature on the bond behaviour of NSM FRP-to-concrete joints;

3) Most experimental studies were focused on simply supported RC beams where NSM FRP reinforcement was applied in a sagging moment region, while little research has been carried out on the use of NSM FRP reinforcement in hogging moment regions (e.g. in $\mathrm{RC}$ frames). In the latter case, future research is needed to clarify the possible difference in the strengthening mechanism, especially in terms of the anchorage failure of the NSM reinforcement;

4) Only a limited number of strength models were proposed for IC interfacial debonding, end interfacial debonding and end cover separation in NSM CFRP RC beams, while no strength model has been established for IC cover separation. Most existing strength 
models for NSM CFRP RC beams are preliminary in nature and have been based on limited understanding of failure mechanisms. Although Teng et al.'s model [28] for end cover separation, proposed based on a comprehensive numerical parametric study, captures the failure mechanism of such failure mode, the accuracy of this model needs to be further verified with more test data;

5) Using U-shaped FRP jackets for end anchorage of NSM CFRP strips was shown to enhance the strengthening efficiency. However, its effect has not been quantitatively investigated and no design method is available now.

\section{Acknowledgement}

The authors are grateful for the financial support received from the National Natural Science

Council through a Discovery Early Career Researcher Award (Project ID: DE140101349) for

the second author. The work presented in this paper was undertaken under the supervision of to Prof. Teng for his contributions to this work.

802

\section{References:}

[1] Teng, J. G., Chen, J. F., Smith, S. T., and Lam, L. (2002). FRP-strengthened RC

[2] Hollaway, L. C. and Teng, J. G., eds. (2008). Strengthening and rehabilitation of civil infrastructures using FRP composites, Woodhead, Cambridge, U.K.

[3] El Hacha, R., and Rizkalla, S. H. (2004). "Near-surface-mounted fiber-reinforced polymer reinforcements for flexural strengthening of concrete structures." $A C I$ Structural Journal, 101(5), 717-726.

[4] De Lorenzis, L., and Teng, J. G. (2007). "Near-surface mounted FRP reinforcement: an emerging technique for strengthening structures." Composites Part B-Engineering, 38(2), 119-143.

[5] Coelho, M.R.F., Sena-Cruz, J.M., Neves, L.A.C. (2015). "A review on the bond behavior of FRP NSM systems in concrete." Construction and Building Materials, 93, 1157-1169. 
817

818

819

820

821

822

823

824

825

826

827

828

829

830

831

832

833

834

835

836

837

838

839

840

841

842

843

844

845

846

847

848

849

850

851

852

853

854

855

856

857

858

859

860

861

862

863

864

865

866

[6] Seracino, R., Jones, N. M., Ali, M. S. M., Page, M. W., and Oehlers, D. J. (2007). "Bond strength of near-surface mounted FRP strip-to-concrete joints." Journal of Composites for Construction, 11(4), 401-409.

[7] Oehlers, D. J., Haskett, M., Wu, C. Q., and Seracino, R. (2008). "Embedding NSM FRP plates for improved IC debonding resistance." Journal of Composites for Construction, 12(6), 635-642.

[8] Al-Mahmoud, F., Castel, A., Francois, R., and Tourneur, C. (2009). "Strengthening of RC members with near-surface mounted CFRP rods." Composite Structures, 91(2), 138-147.

[9] Al-Mahmoud, F., Castel, A., Francois, R., and Tourneur, C. (2010). "RC beams strengthened with NSM CFRP rods and modelling of peeling-off failure." Composite Structures, 92(8), 1920-1930.

[10] Wang, B., Teng, J. G., De Lorenzis, L., Zhou, L. M., Ou, J. P., Jin, W., and Lau, K. T. (2009). "Strain monitoring of RC beams strengthened with smart NSM FRP bars." Construction and Building Materials (Special Issue), 23(4), 1698-1711.

[11] Ceroni, F. (2010). "Experimental performances of RC beams strengthened with FRP materials." Construction and Building Materials, 24(9), 1547-1559.

[12] Soliman, S. M., El-Salakawy, E., and Benmokrane, B. (2010). "Flexural behaviour of concrete beams strengthened with near surface mounted fibre reinforced polymer bars." Canadian Journal of Civil Engineering, 37(10), 1371-1382.

[13] Wahab, N., Soudki, K. A., and Topper, T. (2010). "Mechanism of bond behavior of concrete beams strengthened with near-surface-mounted CFRP rods." Journal of Composites for Construction, 15(1), 85-92.

[14] Ceroni, F., Pecce, M., Bilotta, A., and Nigro, E. (2012). "Bond behavior of FRP NSM systems in concrete elements." Composites Part B-Engineering, 43(2), 99-109.

[15] Ceroni, F., Barros, J.A.O., Pecce, M., Ianniciello, M. (2013). "Assessment of nonlinear bond laws for near-surface-mounted systems in concrete elements." Composites Part b-Engineering, 45 (1), 666-681.

[16] Lee, D., Cheng, L.J., Hui, J.Y.G. (2013). "Bond characteristics of various NSM FRP reinforcements in concrete." Journal of Composites for Construction-ASCE, 17(1), 117-129.

[17] Seo, S.Y., Feo, L. and Hui D. (2013). "Bond strength of near surface-mounted FRP plate for retrofit of concrete structures." Composite Structures, 95, 719-727.

[18] Bilotta, A., Ceroni, F., Di Ludovico, M., Nigro, E., Pecce, M. and Manfredi, G. (2011). "Bond Efficiency of EBR and NSM FRP Systems for Strengthening Concrete Members." Journal of Composites for Construction-ASCE, 15(5), 757-772.

[19] Bilotta, A., Ceroni, F., Nigro, E. and Pecce, M. (2014). "Strain assessment for the design of NSM FRP systems for the strengthening of RC members." Construction and Building Materials, 69, 143-158.

[20] Bilotta, A., Ceroni, F., Nigro, E. and Pecce, M. (2015). "Efficiency of CFRP NSM strips and EBR plates for flexural strengthening of RC beams and loading pattern influence." Composite Structures, 124, 163-175.

[21] Seracino, R., Saifulnaz, M. R. R., and OehlerS, D. J. (2007). "Generic debonding resistance of EB and NSM plate-to-concrete joints." Journal of Composites for Construction, 11(1), 62-70.

[22] Ali, M.S.M., Oehlers, D.J., Seracino, M.C.G. (2008) "Interfacial stress transfer of near surface mounted FRP-to-concrete joints.” Engineering Structures, 30(7), 1861-1868.

[23] Oehlers, D. J., Rashid, R., and Seracino, R. (2008). "IC debonding resistance of groups of FRP NSM strips in reinforced concrete beams." Construction and Building Materials, 22(7), 1574-1582. 
[24] Vasquez, D., and Seracino, R. (2010). "Assessment of the predictive performance of existing analytical models for debonding of near-surface mounted FRP strips." Advances in Structural Engineering, 13(2), 299-308.

[25] Zhang, S.S. and Teng, J.G. (2013). "Interaction forces in RC beams strengthened with near-Surface mounted rectangular Bars." Composites Part B: Engineering, 45(1), 697-709.

[26] Zhang, S.S., Teng, J.G., and Yu, T. (2013). "Bond-slip model for CFRP strips near-surface mounted to concrete." Engineering structures, 56, 945-953.

[27] Zhang, S.S., Teng, J.G., and Yu, T. (2013). "Bond strength model for CFRP strips near-surface mounted to concrete." Journal of Composites for Construction, ASCE, in press [doi:10.1061/(ASCE)CC.1943-5614.0000402].

[28] Teng J.G., Zhang S.S. and Chen J.F. (2016). "Strength model for end cover separation Failure in RC beams strengthened with near-surface mounted (NSM) FRP strips", Engineering Structures, 110, 222-232.

[29] Zhang, S.S. and Yu T. (2016). "Analytical solution for interaction forces in beams strengthened with near-surface mounted round bars", Construction and Building materials, 106, 189-197.

[30] Zhang, S. S., and Teng, J. G. (2010) "Finite element prediction of plate-end cover separation in FRP-strengthened RC beams." Proceedings, 11th International Symposium on Structural Engineering, December18-20, 2010, Guangzhou, China, pp. 1794-1799.

[31] Zhang, S.S., Teng, J.G. (2014). "Finite element analysis of end cover separation in RC beams strengthened in flexure with FRP." Engineering Structures, 75, 550-560

[32] Zhang, S.S. and Teng, J.G. (2015). "End cover separation in RC beams strengthened in flexure with bonded FRP reinforcement: simplified finite element approach", Materials and Structures, in press [doi:10.1617/s11527-015-0645-z].

[33] Borchert, K., and Zilch, K. (2007). "A general bond stress-slip relationship for NSM FRP strips." Proceedings, 8th International Conference on Fibre Reinforced Plastics for Reinforced Concrete Structures, Patras, Greece, July 16-18, 2007 (CD-ROM).

[34] Perera, W. K. K. G., Ibell, T. J., and Darby, A. P. (2009). "Bond behaviour and effectiveness of various shapes of NSM CFRP bars." Proceedings, 9th International Symposium on Fiber-Reinforced Polymers Reinforcement for Concrete Structures (FRPRCS-9), July 13-15, 2009, Sidney, Australia (CD-ROM).

[35] Perera, W. K. K. G., Ibell, T. J., and Darby, A. P. (2013). "Bond characteristics of near surface mounted CFRP bars." Construction and Building Materials, 43, 58-68.

[36] Teng, J.G., Smith, S., Lam, L., Dai, J.G., Yu, T., Wu, Y.F., Chen, G.M. and Zhang, S.S. (2016) "Guide for the strengthening of reinforced concrete structures using FRP composites". To be published by the Hong Kong Society for Composites in Infrastructure.

[37] De Lorenzis, L. (2002). Strengthening of RC Structures with Near Surface Mounted FRP Rods. PhD Thesis, Department of Innovation Engineering, University of Lecce, Italy.

[38] De Lorenzis, L. (2004). "Anchorage length of near-surface mounted fibre-reinforced polymer bars for concrete strengthening-analytical modeling." ACI Structural Journal, 101(3), 375-386.

[39] Rizkalla, S., and Hassan, T. (2002). "Effectiveness of FRP for strengthening concrete bridges." Structural Engineering International, 12(2), 89-95.

[40] Singh, S. B., Reddy, A. L. and Khatri, C. P. (2013). "Experimental and Parametric Investigation of Response of NSM CFRP-Strengthened RC Beams." Journal of Composites for Construction-ASCE, in press. 
917

918

919

920

921

922

923

924

925

926

927

928

929

930

931

932

933

934

935

936

937

938

939

940

941

942

943

944

945

946

947

948

949

950

951

952

953

954

955

956

957

958

959

960

961

962

963

964

965

966

[41] Capozucca, R. and Bossoletti, S. (2014). "Static and free vibration analysis of RC beams with NSM CFRP rectangular rods." Composites Part B-Engineering, 67, 95-110.

[42] Hassan, T. K., and Rizkalla, S. H. (2003). "Investigation of bond in concrete structures strengthened with near surface mounted carbon fiber reinforced polymer strips." Journal of Composites for Construction, ASCE, 7(3), 248-257.

[43] Barros, J. A. O., and Fortes, A. S. (2005). "Flexural strengthening of concrete beams with CFRP laminates bonded into slits." Cement \& Concrete Composites, 27(4), 471-480.

[44] Barros, J. A. O., Dias, S. J. E., and Lima, J. L. T. (2007). "Efficacy of CFRP-based techniques for the flexural and shear strengthening of concrete beams." Cement \& Concrete Composites, 29(3), 203-217.

[45] Teng, J. G., De Lorenzis, L., Wang, B., Rong, L., Wong, T. N., and Lam, L. (2006). "Debonding failures of RC beams strengthened with near-surface mounted CFRP strips." Journal of Composites for Construction, ASCE, 10(2), 92-105.

[46] Aidoo, J., Harries, K. A., and Petrou, M. F. (2006). "Full-scale experimental investigation of repair of reinforced concrete interstate bridge using CFRP materials." Journal of Bridge Engineering, 11(3), 350-358.

[47] Yost, J. R., Gross, S. P., Dinehart, D. W., and Mildenberg, J. J. (2007). "Flexural behavior of concrete beams strengthened with near-surface mounted CFRP strips." ACI Structural Journal, 104(4), 430-437.

[48] Castro, E. K., Melo, G. S., and Nagato, Y. (2007). "Flexural strengthening of RC "T" beams with near surface mounted (NSM) FRP reinforcements." Proceedings, 8th International Conference on Fibre Reinforced Plastics for Reinforced Concrete Structures, Patras, Greece, July 16 to 18, 2007 (CD-ROM).

[49] Kotynia, R. (2007). "Analysis of the flexural response of NSM FRP-strengthened concrete beams." Proceedings, 8th International Conference on Fibre Reinforced Plastics for Reinforced Concrete Structures (FRPRCS-8), Patras, Greece, July 16 to 18, 2007 (CD-ROM).

[50] Novidis, D. G., and Pantazopoulo, S. J. (2007). "Beam tests of NSM - FRP laminates in concrete." Proceedings, 8th International Conference on Fibre Reinforced Plastics for Reinforced Concrete Structures, Patras, Greece, July 16-18, 2007 (CD-ROM).

[51] Thorenfeldt, E. (2007). "Bond capacity of CFRP strips glued to concrete in sawn slits." Proceedings, 8th International Conference on Fibre Reinforced Plastics for Reinforced Concrete Structures, Patras, Greece, July 16 to 18, 2007 (CD-ROM).

[52] Kalayci, A.S., Yalim, B. and Mirmiran, A. (2010). "Construction tolerances and design parameters for NSM FRP reinforcement in concrete beams." Construction and Building Materials, 24(10), 1821-1829.

[53] Dalfre, G.M. and Barros, J.A.O. (2011). "Flexural Strengthening of RC Continuous Slab Strips Using NSM CFRP Laminates." Advances in Structural Engineering, 14(6), 1223-1245.

[54] Peng, H., Zhang, J.R., Cai, C.S. and Liu, Y. (2014). "An experimental study on reinforced concrete beams strengthened with prestressed near surface mounted CFRP strips." Engineering Structures, 79, 222-233.

[55] Sharaky, I.A., Torres, L. and Sallam, H.E.M. (2015). "Experimental and analytical investigation into the flexural performance of RC beams with partially and fully bonded NSM FRP bars/strips." Composite Structures, 122, 113-126.

[56] Capozucca, R., Bossoletti, S., and Montecchiani, S. (2015). "Assessment of RC beams with NSM CFRP rectangular rods damaged by notches." Composite Structures, 128, 322-341.

[57] Wu, G., Dong, Z.Q., Wu, Z.S. and Zhang, L.W. (2014). "Performance and parametric 
981

982

983

984

985

986

987

988

989

990

991

992

993

994

995

996

997

998

999

1000

1001

1002

1003

1004

1005

1006

1007

1008

1009

1010

1011

1012

1013

1014

1015

1016

analysis of flexural strengthening for RC beams with NSM-CFRP bars." Journal of Composites for Construction, 18 (4), DOI: 10.1061/(ASCE)CC.1943-5614.0000451.

[58] Fernandes, P.M.G., Silva, P.M. and Sena-Cruz, J. (2015). "Bond and flexural behavior of concrete elements strengthened with NSM CFRP laminate strips under fatigue loading." Engineering Structures, 84, 350-361.

[59] Barros, J.A.O., Costa, I.G. and Ventura-Gouveia, A. (2011). "CFRP Flexural and Shear Strengthening Technique for RC Beams: Experimental and Numerical Research." Advances in Structural Engineering, 14(3), 551-573.

[60] Nanni, A., Bakis, C. E., and Boothby, T. E. (1995). "Test methods for FRP-concrete systems subjected to mechanical loads: state of the art review." Journal of Reinforced Plastics and Composites, 14(6), 524-558.

[61] Blaschko, M. (2003). "Bond behaviour of CFRP strips glued into slits." Proceedings, 6th International Symposium on Fibre-Reinforced Polymer (FRP) Reinforcement for Concrete Structures, July8-10, 2003, Singapore, p.205-214.

[62] Yan, X., Miller, B., Nanni, A., and Bakis, C. E. (1999). "Characterization of CFRP bars used as near-surface mounted reinforcement." Proceedings, 8th International Structural Faults and Repair Conference, Edinburgh (Scotland), 1999 ( CD-ROM).

[63] Li, R., Teng, J. G., and Yue, Q. R. (2005). "Experimental study on bond behavior of NSM CFRP strips-concrete Interface." Industrial Construction, 35(8), 31-35 (in Chinese).

[64] Shield, C. K., French, C. W., and Milde, E. (2005). "The effect of adhesive type on the bond of NSM tape to concrete." ACI SP230: the 7th International Symposium on Fiber-Reinforced Polymer (FRP) Reinforcment for Concrete Structures, American Concrete Institute, November, p.355-372.

[65] Rashid, R., Oehlers, D. J., and Seracino, R. (2008). "IC debonding of FRP NSM and EB retrofitted concrete: plate and cover interaction tests." Journal of Composites for Construction, 12(2), 160-167.

[66] Kotynia, R. (2012). "Bond between FRP and concrete in reinforced concrete beams strengthened with near surface mounted and externally bonded reinforcement." Construction and Building Materials, 32, 41-54.

[67] Teng, J.G., Zhang, S.S., Dai, J.G. and Chen, J.F. (2013). "Three-dimensional meso-scale finite element modeling of bonded joints between a near-surface mounted FRP strip and concrete." Computers \& Structures, 117, 105-117.

[68] Dai, J.G., Ueda, T., Sato, Y. (2005). "Development of the nonlinear bond stress-slip model of fiber reinforced plastics sheet-concrete interfaces with a simple method." Journal of Composites for Construction, 9(1), 52-62.

[69] Lu, X.Z., Teng, J.G., Ye, L.P., Jiang, J.J. (2005). "Bond-slip models for FRP sheets/plates bonded to concrete." Engineering Structures, 27(6), 920-937.

[70] Sena Cruz, J. M., and Barros, J. A. O. (2004). "Bond between near-surface mounted carbon-fiber-reinforced polymer laminate strips and concrete." Journal of Composites for Construction, ASCE, 8(6), 519-527.

[71] De Lorenzis, L., and Nanni, A. (2002). "Bond between near-surface mounted fiber-reinforced polymer rods and concrete in structural strengthening." ACI Structural Journal, 99(2), 123-132.

[72] De Lorenzis, L., Lundgren, K., and Rizzo, A. (2004). "Anchorage length of near-surface mounted fibre-reinforced polymer bars for concrete strengthening-experimental investigation and numerical modeling." ACI Structural Journal, 101(2), 269-278.

[73] De Lorenzis, L., Rizzo, A., and La Tegola, A. (2002). "A Modified pull-out test for bond of near-surface mounted FRP rods in concrete." Composites Part B: Engineering, 
1017

1018

1019

1020

1021

1022

1023

1024

1025

1026

1027

1028

1029

1030

1031

1032

1033

1034

1035

1036

1037

1038

1039

1040

1041

1042

1043

1044

1045

1046

1047

1048

1049

1050

1051

1052

1053

1054

1055

1056

1057

1058

1059

1060

1061

1062

1063

1064

1065

1066

33(8), 589-603.

[74] Sena Cruz, J. M., and Barros, J. A. O. (2004). "Modeling of bond between near-surface mounted CFRP laminate strips and concrete." Computers and Structures, 82(17-19), 1513-1521.

[75] Eligehausen, R. Popov, E.P. and Bertero, V.V. (1983). "Local bond stress-slip relationships of deformed bars under generalized excitations." Report No. 83/23, EERC, Berkeley, CA: University of California.

[76] CEB-FIP. (1993). "Model Code 90.” Lausanne; 1993.

[77] Teng, J. G., Zhang, S. S., and Dai, J. G. (2009). "Finite element modelling of FRP strips near-surface mounted to concrete." Proceedings, 9th International Symposium on Fiber-Reinforced Polymers Reinforcement for Concrete Structures (FRPRCS-9), July 13-15, 2009, Sidney, Australia (CD-ROM).

[78] Chen, J.F. and Teng, J.G. (2001). "Anchorage strength models for FRP and steel plates bonded to concrete." Journal of Structural Engineering, ASCE, 127(7), 784-791.

[79] Yao, J., Teng, J.G. and Chen, J.F. (2005). "Experimental study on FRP-to-concrete bonded joints." Composites Part B: Engineering, 36(2), 99-113.

[80] Yuan, H., Teng, J.G., Seracino, R., Wu, Z.S., and Yao, J. (2004). "Full-range behavior of FRP-to-concrete bonded joints." Engineering Structures, 26(5), 553-565.

[81] Yuan, H., Wu, Z.S., and Yoshizawa, H. (2001). "Theoretical solutions on interfacial stress transfer of externally bonded steel/composite laminates." Journal of Structural Mechanics and Earthquake Engineering, JSCE, 18(1), 27-39.

[82] Bianco, V., Barros, J.A.O. and Monti, G. (2009). "Bond Model of NSM FRP strips in the context of the Shear Strengthening of RC beams", Journal of Structural Engineering - ASCE, 135(6), 619-631.

[83] Bianco, V., Barros, J.A.O. and Monti, G. (2010). "New approach for modeling the contribution of NSM FRP strips for shear strengthening of RC beams", Journal of Composites for Construction - ASCE, 14(1), 36-48.

[84] Dalfré, G. and Barros, J.A.O. (2013). "NSM technique to increase the load carrying capacity of continuous RC slabs", Engineering Structures, 56, 137-153.

[85] Breveglieri, M., Barros, J.A.O., Dalfré, G.M. and Aprile, A. (2013). "A parametric study on the effectiveness of the NSM technique for the flexural strengthening of continuous RC slabs", Composites Part B-Engineering, 43(4), 1970-1987.

[86] Sena Cruz, J., Barros, J.A.O., Bianco, V., Bilotta, A., Bournas, D., Ceroni, F.,Dalfré, G., Kotynia, R., Monti, G., Nigro, E. and Triantafillou, T. (2016). NSM Systems, Design Procedures for the Use of Composites in Strengthening of Reinforced Concrete Structures: State-of-the-Art Report of the RILEM Technical Committee 234-DUC (pp. 303-348). Dordrecht: Springer Netherlands.

[87] Firmo, J.P. and Correia, J.R. (2016). "Fire behaviour of thermally insulated RC beams strengthened with NSM-CFRP strips: Experimental study", Composites Part B-Engineering, 76, 112-121.

[88] Benedetti, A., Fernandes, P., Granja, J.L., Sena-Cruz, J. and Azenha, M. (2016). "Influence of temperature on the curing of an epoxy adhesive and its influence on bond behaviour of NSM-CFRP systems", Composites Part B-Engineering, 89, 219-229.

[89] Yu, B.L. and Kodur, V. (2014). "Effect of temperature on strength and stiffness properties of near-surface mounted FRP reinforcement", Composites Part B-Engineering, 58, 510-517.

[90] Zhu, H., Wu, G., Zhang, L., Zhang, J.F. and Hui, D. (2014). "Experimental study on the fire resistance of RC beams strengthened with near-surface-mounted high-T-g BFRP", Composites Part B-Engineering, 60, 680-687.

[91] Teng, J. G., Yuan, H. and Chen, J. F. (2006). "FRP-to-concrete interfaces between two 
adjacent cracks: Theoretical model for debonding failure." International Journal of Solids and Structures, 43(18-19), 5750-5778.

[92] Oehlers, D. J., Liu, I. S. T., Seracino, R. (2005). "Shear deformation debonding of adhesively bonded plates." Structures \& Buildings, 158(Issue SB1), 77-84.

[93] Oehlers, D. J., Liu, I. S. T., Seracino, R., and Ali, M. S. M. (2004). "Prestress model for shear deformation debonding of FRP- and steel-plated RC beams." Magazine of Concrete Research, 56(8), 475-486.

[94] Teng, J. G., and Yao, J. (2007). "Plate end debonding in FRP-plated RC beams-II: strength model." Engineering Structures, 29(10), 2472-2486.

[95] Malek, A. M., Saadatmanesh, H., and Ehsani, M. R. (1998). "Prediction of failure load of R/C beams strengthened with FRP plate due to stress concentration at the plate end." ACI Structural Journal, 95(1), 142-152.

[96] Zhang, J. P. (1997). "Diagonal cracking and shear strength of reinforced concrete beams." Magazine of Concrete Research, 49(178), 55-65.

[97] Zhang, S., Raoof, M., and Wood, L. A. (1995). "Prediction of peeling failure of reinforced-concrete beams with externally bonded steel plates." Proceedings, the Institution of Civil Engineers-Structures and Buildings, 110(3), 257-268.

[98] Wang, C.Y. and Ling, F.S. (1998). "Prediction model for the debonding failure of cracked RC beams with externally bonded FRP sheets." Proceedings, $2^{\text {nd }}$ International Conference of Composites in Infrastructure (ICCI), 1998, Arizona, USA, p. 548-562.

[99] De Lorenzis, L., and Nanni, A. (2003). "Proposed design procedure of NSM FRP reinforcement for strengthening of RC beams." Proceedings, 6th International Symposium on FRP Reinforcement for Concrete Structures, Singapore, 1455-1464.

[100] Raoof, M., and Zhang, S. (1997). "An insight into the structural behaviour of reinforced concrete beams with externally bonded plates." Proceedings of the Institution of Civil Engineers-Structures and Buildings, 122(4), 477-492.

[101] Hussain, M., Sharif, A., Basunbul, I. A., Baluch, M. H. and Alsulaimani, G. J. (1995). "Flexural behavior of precracked reinforced-concrete beams strengthened externally by steel plates", ACI Structural Journal, 92(1), 14-22.

[102] Sallam, H.E.M., Saba, A.M., Shahin, H.H. and Abdel-Raouf, H. (2004). "Prevention of peeling failure in plated beams",Journal ofAdvanced Concrete Technology, 2(3), 419-429.

[103] Demakos, C. and Koutsoukos, D. (2003). "Effective strengthening of reinforced concrete beams with anchored FRPs", Recent Advances in Composite Materials. Springer.

[104] Smith, S. T. and Teng, J.G. (2003). "Shear-bending interaction in debonding failures of FRP-plated RC beams", Advances in Structural Engineering, 6(3), 183-99.

[105] Piamanmas, A. and Pornpongsaroj, P. (2004). "Peeling behaviour of reinforced concrete beams strengthened with CFRP plates under various end restraint conditions", Magazine of Concrete Research, 56(2), 73-81.

[106] Kalfat, R., Al-Mahaidi, R. and Smith, S.T. (2013). "Anchorage devices used to improve the performance of reinforced concrete beams retrofitted with a FRP composites: State-of-the-art review", Journal of Composites for Construction, ASCE,17(1), 14-33.

[107] Grelle, S.V. and Sneed, L.H. (2013). "Review of anchorage systems for externally-bonded FRP laminates", International Journal of Concrete Structures and Materials, 7(1),17-33

[108] Skuturna, T. and Valivonis, J. (2016). "Experimental study on the effect of anchorage systems on RC beams strengthened using FRP", Composites Part B-Engineering, 91, 
1115

1116

1117

1118

1119

1120

283-290.

[109] Hosen,M., Jumaat, M.Z. and Islam, S. (2015). "Inclusion of CFRP-Epoxy Composite for End Anchorage in NSM-Epoxy Strengthened Beams", Advances in Materials Science and Engineering, 2015. 


\section{Figures}

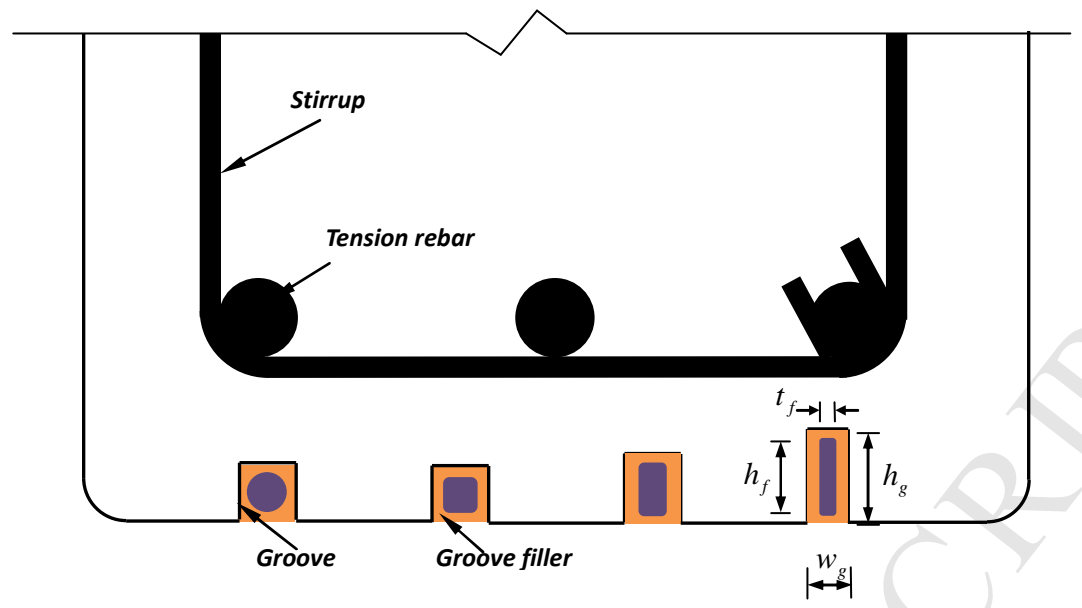

Fig. 1. Schematic of NSM FRP strengthening systems

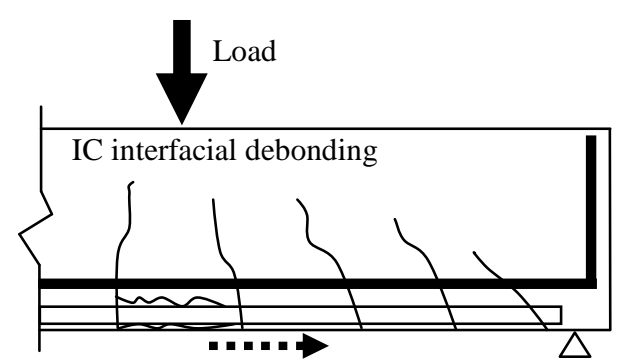

(a) IC interfacial debonding

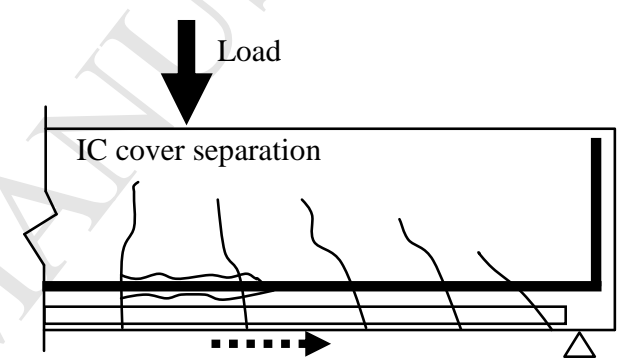

(b) IC cover separation

Fig. 2. Schematic of the IC debonding

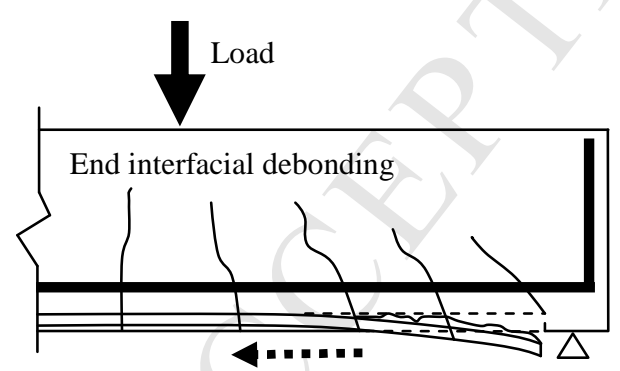

(a) End interfacial debonding

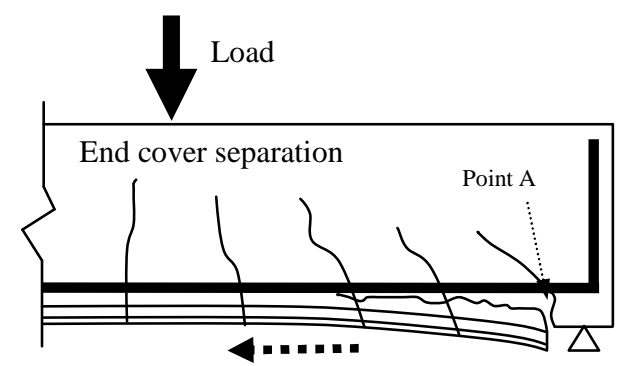

(b) End cover separation

Fig. 3. Schematic of the end debonding

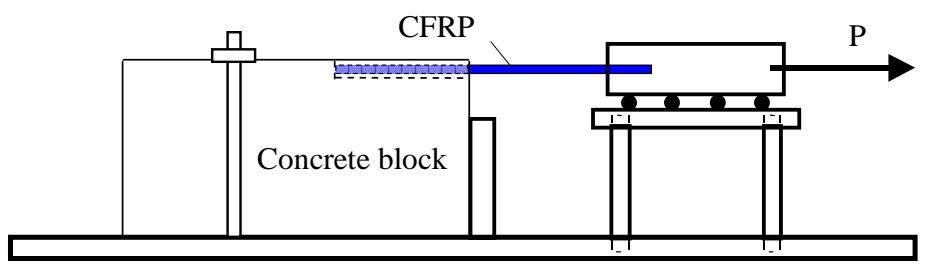


Fig. 4. Test setup of NSM FRP bonded joints
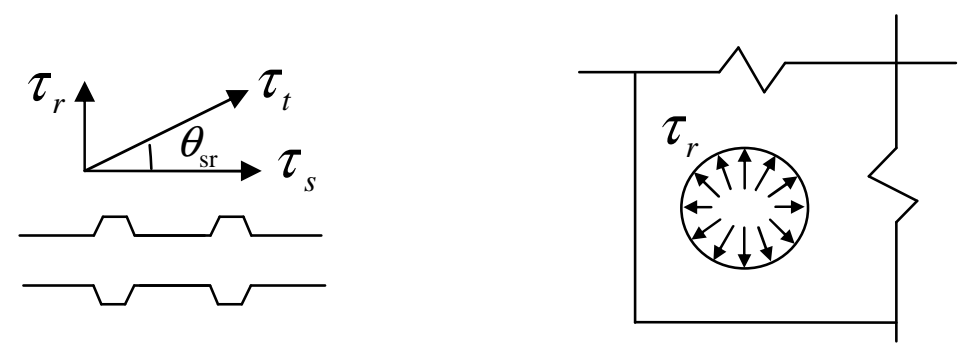

Fig. 5. Bond stresses between steel and concrete

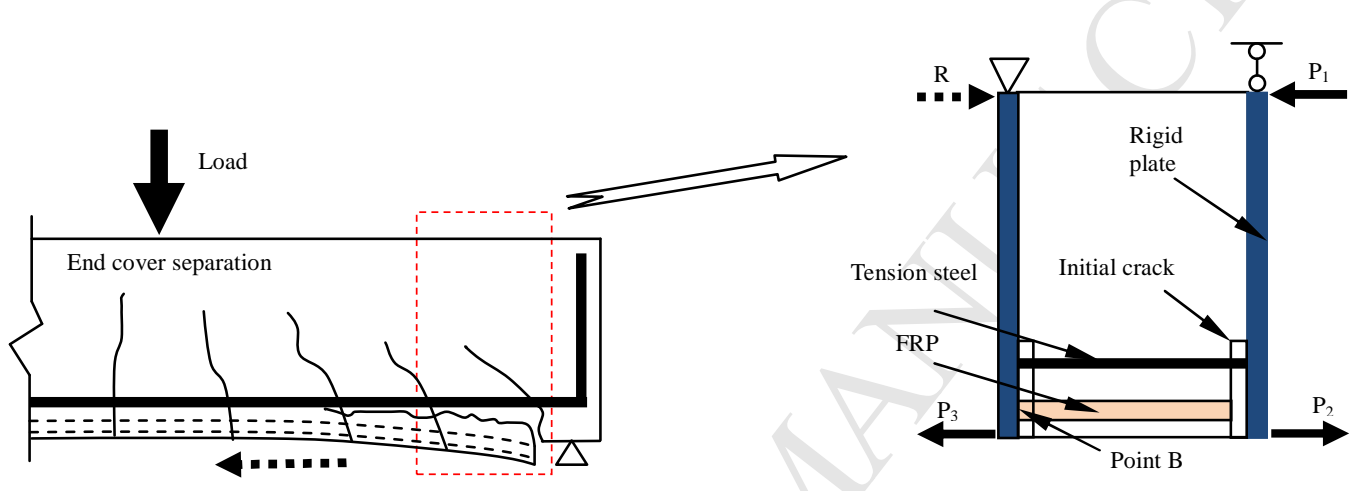

Fig. 6. Simplified FE model 